\title{
REVIEW: FRONTIERS IN PHARMACOLOGY
}

\section{Human African trypanosomiasis: pharmacological re-engagement with a neglected disease}

\author{
MP Barrett ${ }^{1}$, DW Boykin ${ }^{2}, \mathrm{R}$ Brun $^{3}$ and RR Tidwell ${ }^{4}$ \\ ${ }^{1}$ Division of Infection and Immunity, Institute of Biomedical and Life Sciences, The Glasgow Biomedical Research Centre, University \\ of Glasgow, Glasgow, UK; ${ }^{2}$ Department of Chemistry, Georgia State University, Atlanta, GA, USA; ${ }^{3}$ Swiss Tropical Institute, Basel, \\ Switzerland and ${ }^{4}$ Department of Pathology and Laboratory Medicine, University of North Carolina at Chapel Hill, Chapel Hill, \\ NC, USA
}

\begin{abstract}
This review discusses the challenges of chemotherapy for human African trypanosomiasis (HAT). The few drugs registered for use against the disease are unsatisfactory for a number of reasons. HAT has two stages. In stage 1 the parasites proliferate in the haemolymphatic system. In stage 2 they invade the central nervous system and brain provoking progressive neurological dysfunction leading to symptoms that include the disrupted sleep wake patterns that give HAT its more common name of sleeping sickness. Targeting drugs to the central nervous system offers many challenges. However, it is the cost of drug development for diseases like HAT, that afflict exclusively people of the world's poorest populations, that has been the principal barrier to new drug development and has led to them becoming neglected. Here we review drugs currently registered for HAT, and also discuss the few compounds progressing through clinical trials. Finally we report on new initiatives that might allow progress to be made in developing new and satisfactory drugs for this terrible disease.
\end{abstract}

British Journal of Pharmacology (2007) 152, 1155-1171; doi:10.1038/sj.bjp.0707354; published online 9 July 2007

Keywords: human African trypanosomiasis; sleeping sickness; melarsoprol; suramin; pentamidine; eflornithine; nifurtimox; furamidine; pafuramidine; neglected disease

\begin{abstract}
Abbreviations: AIDS, acquired immunodeficiency syndrome; apoL1, apolipoprotein L1; CSF, cerebrospinal fluid; DFMO, difluoromethylornithine; DNDi, the Drugs for Neglected Diseases initiative; FDA, US Food and Drug Administration; FIND, the Foundation for innovative new diagnostics; HAPT1, high-affinity pentamidine transporter 1; HAT, human African trypanosomiasis; LDL, low-density lipoprotein; MSF, Médecins sans Frontières; ODC, ornithine decarboxylase; PCP, Pneumocystis carinii pneumonia; TbAT1, T. brucei adenosine transporter 1 (the P2 transporter); UNC, University of North Carolina at Chapel Hill; WHO, World Health Organization
\end{abstract}

\section{Introduction}

Human African trypanosomiasis (HAT), perhaps better known as sleeping sickness once the causative trypanosome parasites have established within the central nervous system (CNS) (Barrett et al., 2003), is considered as a neglected disease (Remme et al., 2002). Neglected diseases are those ailments which affect people from among the world's poorest populations, for which satisfactory treatment does not exist, but for which the investment required to bring new compounds to market has proven a major disincentive to drug development.

At the end of the twentieth century, nearly half a million people were estimated to be afflicted by HAT (Barrett et al.,

Correspondence: Dr MP Barrett, Division of Infection and Immunity, Institute of Biomedical and Life Sciences, The Glasgow Biomedical Research Centre, University of Glasgow, Glasgow G12 8TA, UK.

E-mail: m.barrett@bio.gla.ac.uk

Received 31 January 2007; revised 25 April 2007; accepted 22 May 2007; published online 9 July 2007
2003). Ironically, trypanosomes were among the first organisms to be targeted by synthetic drugs and Paul Ehrlich, 'the father of chemotherapy' (Drews, 2004), chose these organisms as a model on which to test his ideas. During the first two-thirds of the twentieth century, several compounds were introduced to treat HAT (Williamson, 1962, 1970; Apted, 1970). Sanofi-Aventis and Bayer between them currently produce all of the licensed anti-HAT drugs and donate them free of charge to the World Health Organization (WHO) who distributes them in Africa.

The African trypanosome is a popular organism for biological research. Much is known about trypanosome biochemistry and its genome sequence was published in 2005 (Berriman et al., 2005). The parasite is amenable to drug target validation through genetic means (Barrett et al., 1999) and simple screens are available to test drugs (for example, Raz et al., 1997). However, only a single compound, eflornithine, has been registered for use against HAT in the 
last 50 years, a reflection of the gap between our understanding about the organism and our capacity to develop new drugs. New initiatives discussed in the final part of this review promise to close the gap.

Two subspecies of the Kinetoplastid protozoans, Trypanosoma brucei, cause human disease. T. $b$. rhodesiense is responsible for an acute form in Eastern and Southern Africa (Fevre et al., 2005), while T. b. gambiense causes a chronic form in West and Central Africa (Figure 1). Generally the rhodesiense form of the disease is fatal within weeks to months of inoculation through the bite of an infected tsetse fly vector (Figure 2), while the gambiense form takes years to develop. There appears to be some geographical variance in disease manifestation. For example, in Malawi, patients carry $T$. $b$. rhodesiense and yet harbour the parasites without their causing CNS-involved disease for many years (MacLean et al., 2004). Sporadic reports of other trypanosome species causing disease in humans have appeared. These include T. congolense (Truc et al., 1998) and T. evansi (Joshi et al., 2005), which normally infect only animals. Generally, however, a non-immune mechanism of killing, involving a trypanosome lytic factor, believed to be apolipoprotein L1 (apoL1) (Pays et al., 2006) and possibly other components of highdensity lipoprotein fractions (Smith et al., 1995), prevents most species of African trypanosome from establishing infections in humans. The single reported case of a T. evansi infection in man involved a patient who lacked apoL1

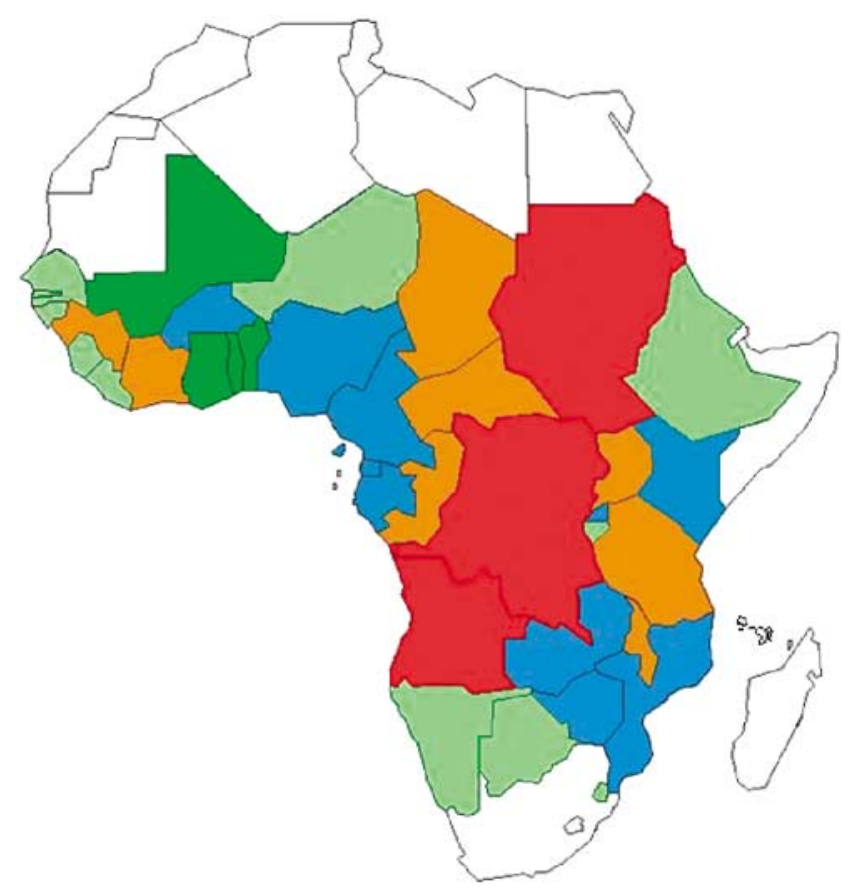

Figure 1 A map of countries infected with HAT. The countries shown in colour have historically reported HAT. Those countries coloured in red are currently reporting in excess of 1000 cases per year. Those in brown currently report between 50 and 1000 cases per year. Those in blue report fewer than 50 cases per year, while those in green currently report no cases of HAT. Nearly $97 \%$ of all reported cases are caused by $T$. b. gambiense. T. b. rhodesiense is found in East and Southern Africa. (Figure courtesy of Dr Pere Simarro at the World Health Organization.) HAT, human African trypanosomiasis.
(Vanhollebeke et al., 2006). T. b. gambiense was responsible for the epidemics that marked the end of the twentieth century. A concerted WHO-led campaign to bring the disease under control has made an impact in recent years reducing the number of cases significantly (Barrett, 2006; Anonymous, 2006).

Animal reservoirs play an important role in the epidemiology of $T$. $b$. rhodesiense, but are less important for $T . b$. gambiense although both wild (Njiokou et al., 2006) and domestic (Simo et al., 2006) animals have been found infected with this subspecies. Vector control can curb transmission (Allsopp, 2001) and was successfully employed in recent years to eradicate trypanosomiasis from Zanzibar using extensive trapping, followed by the sterile insect technique (Vreysen et al., 2000). However, it has proven difficult to implement tsetse control in a coordinated fashion on the African mainland. A process of antigenic variation, where parasites repeatedly change the surface coat that interfaces with the immune system, renders the prospects of vaccination poor (McCulloch, 2004). Drugs are central to efforts to control HAT.

Current drugs (Pepin and Milord, 1994; Barrett, 2000; Legros et al., 2002; Fairlamb, 2003; Burri et al., 2004; Brun and Balmer, 2006) all suffer drawbacks. Toxicity (sometimes severe), the need for parenteral administration, lack of a guaranteed supply and increasing incidence of treatment failure with some drugs make the situation difficult. The only compound in advanced phase III clinical trials is the orally available prodrug, pafuramidine maleate (DB289) (Boykin et al., 1996; Ansede et al., 2004), which is metabolized systemically to the diamidine, furamidine (DB75). It is the first compound whose development as a trypanocide might be considered to have approached that typical for registration of a new chemical entity for therapeutic purposes today. However, it is active only in stage 1 disease. Other drugs are urgently required, especially for stage 2 patients as it is generally only this cohort who present at HAT clinics once neurological symptoms are manifest. This review discusses those drugs already in use for HAT and also the few compounds in different stages of the development process, leading to a discussion of new initiatives in drug development for HAT.

\section{Drugs registered for HAT chemotherapy}

Four licensed compounds are used against HAT today, depending on the causative subspecies and whether parasites have initiated disease of the CNS (stage 2) or not (stage 1) (Pepin and Milord, 1994; Denise and Barrett, 2001; Keiser et al., 2001; Fairlamb, 2003; Burri et al., 2004; Brun and Balmer, 2006). Two compounds are used against stage 1 disease: suramin and pentamidine. Against stage 2 disease, melarsoprol (active against $T . \quad b$. gambiense and $T . \quad b$. rhodesiense) and eflornithine (only useful against $T . \quad b$. gambiense) can be used. Nifurtimox, alone or in combination with other drugs, particularly with eflornithine, is being considered as an option for melarsoprol-refractory late-stage disease, or even more widely (Priotto et al., 2006). 


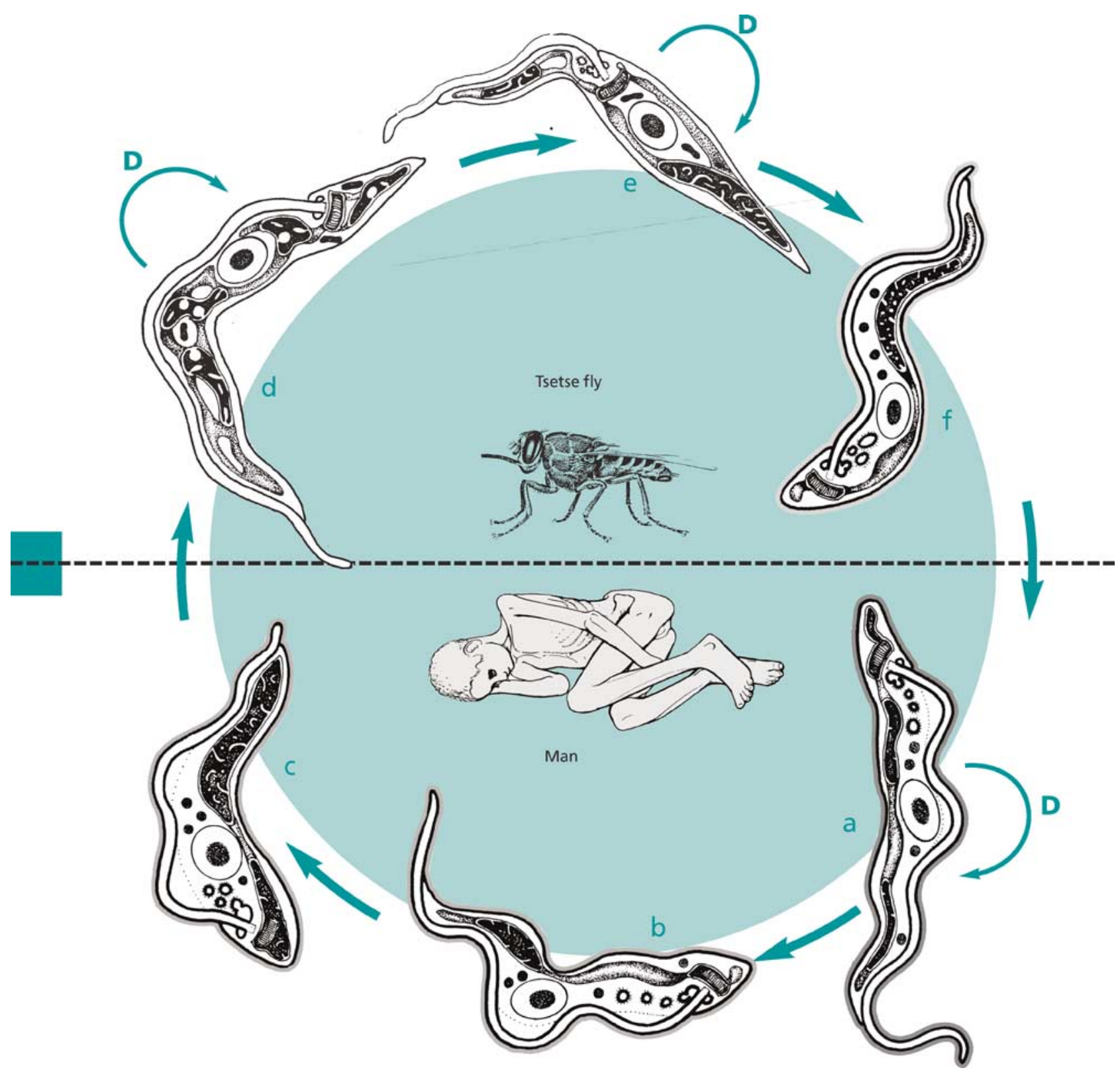

Figure 2 The life cycle of Trypanosoma brucei. Parasites are transmitted to man by the bite of an infected tsetse fly. Within man, the parasites proliferate first within the haemolymphatic system and later invade the CNS. Proliferative bloodstream slender form parasites (a), transform via an intermediate form (b) into non-proliferative stumpy forms (c). These are pre-adapted to survive within a tsetse fly where they transform into procyclic forms (d) that proliferate in the midgut of this environment before passing through various other stages including the epimastigote form (e) until transforming into metacyclic trypomastigotes (f) in the salivary glands. These forms are preadapted for life in the mammalian host when injected during a bloodmeal. Forms that are capable of division are labelled with a D. CNS, central nervous system.

\section{Drugs used in early-stage disease}

Provided HAT is diagnosed sufficiently early, suramin or pentamidine can be used. Their ease of administration and relative safety make them preferable to drugs used for stage 2 disease. The rapidly proliferating parasitaemia typical of the rhodesiense form of the disease can provoke early presentation by patients at clinic. However, the symptoms of earlystage gambiense disease do not normally extend beyond a general malaise common place in rural Africa. These patients are unlikely to present passively before late-stage involve- ment. Efforts to improve diagnosis (Chappuis et al., 2005a) are needed to accompany improved treatment.

\section{Pentamidine}

Background. Pentamidine isethionate (Figure 3) is currently produced by Sanofi-Aventis as pentacarinat in $200 \mathrm{mg}$ ampoules for intramuscular injection. It is used against gambiense disease but not usually rhodesiense. The drug is donated, free of charge, to WHO for distribution. Four milligrams per kilogram given daily, or on alternate days, 


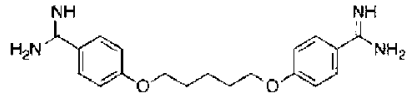

Pentamidine
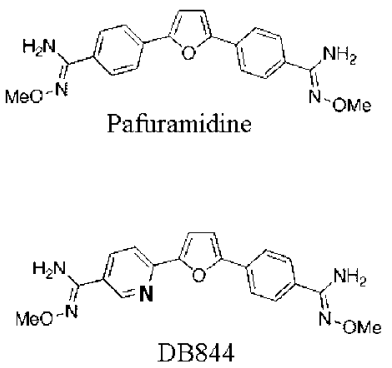
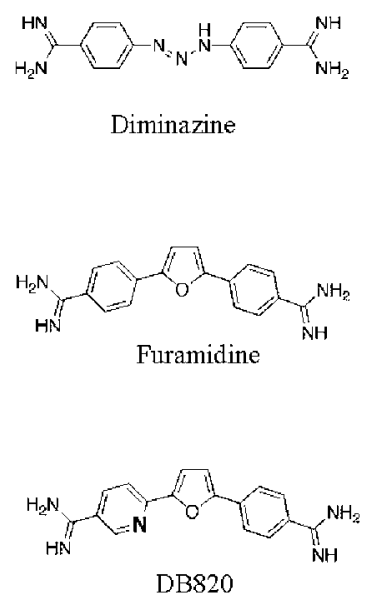

Figure 3 Structures of some important trypanocidal diamidines.

for 7-10 days are typical schedules (Sands et al., 1985; Burri et al., 2004).

Modes of action and resistance mechanisms. Pentamidine is concentrated to high levels (in the low millimolar range) by trypanosomes exposed to low micromolar concentrations of the drug (Damper and Patton, 1976a; Berger et al., 1995; Carter et al., 1995; de Koning, 2001a; Bray et al., 2003). Uptake is carrier mediated (Damper and Patton, 1976b). The drug enters principally via the P2 aminopurine permease which also transports melaminophenyl arsenicals (Carter et al., 1995). A high-affinity pentamidine transporter 1 (HAPT1) and a low-affinity pentamidine transporter 1 (LAPT1) also contribute to pentamidine uptake (de Koning, 2001a); hence parasites selected for melaminophenyl arsenical resistance that lack the $\mathrm{P} 2$ transporter often remain sensitive to pentamidine (Frommel and Balber, 1987; Fairlamb et al., 1992a; de Koning, 2001b; Matovu et al., 2003). One laboratory line selected for pentamidine resistance continued to accumulate drug to high levels and retained activity of the P2 transporter (Berger et al., 1995). This parasite line was of much reduced virulence in rodents, which might indicate that the development of resistance to pentamidine is associated with substantial fitness costs, rendering the propagation of resistant lines in the field unlikely (Berger et al., 1995; Bray et al., 2003). Another line, this time selected for pentamidine resistance in a cell line already lacking the P2 transporter (TbAT1, T. brucei adenosine transporter 1) (Matovu et al., 2003), also developed a reduced virulence phenotype, but on this occasion pentamidine uptake was greatly reduced and the HAPT1 transporter was reported to be lost (Bridges et al., 2007).

While pentamidine's uptake into trypanosomes has been characterized in detail, its definitive mode of action is not certain (Berger et al., 1993; Werbovetz, 2006). The mitochondrion appears to be a target for pentamidine in various species including yeast (Ludewig et al., 1994). In Leishmania parasites (close relatives of trypanosomes), fluorescent analogues of pentamidine accumulate preferentially in this compartment and mitochondrial damage (Hentzer and
Kobayasi, 1977; Croft and Brazil, 1982) precedes cell death. Pentamidine resistance in Leishmania correlates to a reduction in the mitochondrial membrane potential (Basselin and Robert-Gero, 1998; Basselin et al., 2002; Mukherjee et al., 2006). As a di-cation, pentamidine interacts electrostatically with cellular polyanions. It binds DNA, including the unique intercatenated network of circular DNA molecules termed the kinetoplast, which make up the mitochondrial genome of all kinetoplastid flagellates (Simpson, 1986). However, bloodstream form $T$. brucei can retain viability, given time to adapt, when the kinetoplast has disintegrated (a state termed dyskinetoplastidy (Schnaufer et al., 2002)), although mitochondrial DNA can remain dispersed within the mitochondrion in some of these cases. Dyskinetoplastic parasites are slightly less sensitive than wild-type cells to diamidines. Fluorescent diamidines, for example, furamidine (Stewart et al., 2005; Mathis et al., 2006) and stilbamidine (Hawking and Smiles, 1941) also accumulate rapidly in the kinetoplast, and they also sequester in another class of organelle believed to be acidocalcisomes (Mathis et al., 2006). Whether the localization correlates with activity is not certain. Another suspected target, $S$-adenosylmethionine decarboxylase, was ruled out because Leishmania parasites overexpressing this enzyme are equally susceptible to pentamidine as wild-type cells (Roberts et al., 2006).

Pharmacology. Pentamidine's use against Pneumocystis carinii pneumonia in AIDS (acquired immunodeficiency syndrome) patients has contributed to the increased interest in understanding the pharmacokinetics of the drug (Conte, 1991). Other studies have looked specifically at the situation in HAT patients (Bronner et al., 1991). The drug has a large volume of distribution and long terminal half-life (elimination times running into weeks after a typical course). Extensive tissue retention and binding to serum proteins contribute to this. The long half-life of pentamidine explains why the drug had some success in prophylactic campaigns in west and central Africa in the mid-twentieth century (Waddy, 1970), a practice that is no longer recommended.

The drug is given by injection because, as expected for a highly charged molecule $\left(\mathrm{p} K_{\mathrm{a}}\right.$ of 11.4 ), pentamidine is not readily absorbed from the intestine. Intramuscular injection is preferred over intravenous injection since this latter route is associated with increased risk of hypotension. Although generally useful only in stage 1 disease, pentamidine might have some activity against parasites in cerebrospinal fluid (CSF), in what has been called 'early-late-stage disease', when white cell counts are still low (appearance of white blood cells in CSF accompanies stage 2 disease) and parasites have only recently entered CSF (Doua et al., 1996). Low levels of pentamidine (below 1\% of plasma levels) have been measured in CSF (Bronner et al., 1991). Pentamidine is extensively metabolized (Berger et al., 1992) with cytochrome P450-dependent oxygenases playing a key role.

The drug is quite toxic. Lowering of blood glucose levels is common with hypotension evident in $10 \%$ of treated cases. Other toxic effects include pain at the site of injection, nephrotoxicity, leucopenia and liver enzyme abnormalities (Sands et al., 1985; Doua and Yapo, 1993). 
Pentamidine is highly trypanocidal (with $\mathrm{IC}_{50}$ values in vitro in the order of $1-10 \mathrm{~nm}$ in a typical 3-day drug sensitivity assay). The time required to kill the parasites is dependent on dose with increasing doses causing progressively faster killing (Miezan et al., 1994).

Given the drug's toxicity, decreasing overall exposure is desirable. Since parasites are killed on exposure to just $10 \mathrm{~nm}$ for 3 days, and since pentamidine's pharmacokinetics ensures concentrations several orders of magnitude above this level are maintained for several days after the termination of drug administration, the prospects of using a 3-day course are currently being investigated.

\section{Suramin}

Background. Suramin (Figure 4) is a polysulphonated symmetrical naphthalene derivative and was first used against sleeping sickness in 1922 (Voogd et al., 1993). This followed Ehrlich's demonstration that other naphthalene dyes had trypanocidal activity due to selective accumulation by trypanosomes (trypan blue, named for its trypanocidal activity, is still used in mammalian cell viability assays). As there is renal clearance of these naphthalenes, suramin's colourlessness was an important factor behind its development. Suramin is currently donated to WHO by Bayer as Germanin (Bayer 205). Reports of treatment failures from gambiense foci in the 1950s and the fact that pentamidine is easier to administer led to suramin being used mainly for rhodesiense cases today. The drug has been considered for other conditions, particularly in androgen-independent prostate cancer (Kaur et al., 2002). The fact that the drug inhibited retroviral reverse transcriptase (Mitsuya et al., 1984) and also interfered with HIV binding to CD ${ }^{+}$cells led to well-publicized, but unsuccessful, trials against HIV/ AIDS.

Modes of action and resistance mechanisms. Many hypotheses as to suramin's mode of trypanocidal action have been
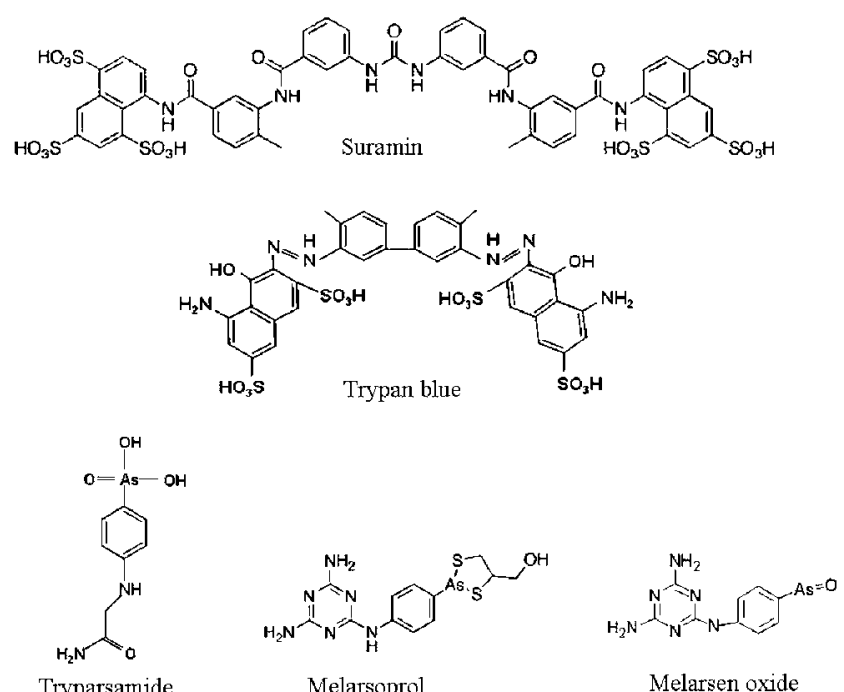

Figure 4 Structures of suramin, trypan blue and some important trypanocidal arsenicals. proposed, but none proven. With six negative charges, the drug binds, by electrostatic interaction, to many enzymes. Suramin is around a hundred fold less active against procyclic form trypanosomes, that normally reside in tsetse flies, than against bloodstream forms (Scott et al., 1996). Since glycolysis is essential to bloodstream forms but not procyclic forms (Fairlamb and Bowman, 1977, 1980; Besteiro et al., 2005) and because suramin inhibits a number of glycolytic enzymes (Wierenga et al., 1987), glycolysis has been proposed as a likely target. However, any number of other pathways too could be targeted by the drug. For example, it is a competitive inhibitor of 6-phosphogluconate dehydrogenase, an enzyme of the pentose phosphate pathway (Hanau et al., 1996).

Endocytosis appears to be the most likely route of entry (Fairlamb and Bowman, 1980). Because of its high avidity binding to many serum proteins, including low-density lipoprotein (LDL) (Vansterkenburg et al., 1993), it was suggested that it might enter while bound to LDL (Bastin et al., 1996; Coppens and Courtoy, 2000; Green et al., 2003). However, in procyclic cells, at least, manipulation of different vesicular transport systems affects uptake of LDL and suramin independently of each other (Pal et al., 2002). The extremely high rate of fluid-phase endocytosis displayed by bloodstream form trypanosomes (Engstler et al., 2004) could potentially explain uptake parameters of suramin into T. brucei without a requirement for a particular receptor, although this is untested.

Reports on suramin resistance in the field are rare (Barrett, 2003). However, resistance can be selected readily in the laboratory (Scott et al., 1996). The drug is also employed as a veterinary trypanocide and resistance has been noted in species of trypanosome, for example, T. evansi, that infect animals (Mutugi et al., 1994; El Rayah et al., 1999) although mechanisms of resistance are not understood.

Pharmacology. Poor intestinal absorption and a local irritation if given intramuscularly mean that suramin is best given by slow intravenous injection (Voogd et al., 1993). A course of five injections, every 3-7 days, over a 4 -week period is typical. Most of the drug (>99\%) binds to serum proteins. Suramin does not cross the blood-brain barrier to levels capable of killing trypanosomes in the CSF at doses given in treatment of stage 1 disease (although in mice, very large doses $\left(>80 \mathrm{mg} \mathrm{kg}^{-1}\right)$ are capable of curing a stage 2 model of the disease (Jennings, 1995)).

The use of the drug in AIDS and cancer clinical trials improved knowledge of its pharmacology (Collins et al., 1986). The elimination terminal half-life is very long (for example, 41-78 days was reported in one study (Eisenberger and Reyno, 1994)).

In vitro, exposure to $1 \mu \mathrm{g} \mathrm{kg}^{-1}$ for $24 \mathrm{~h}$ is sufficient to kill trypanosomes. Thus with levels higher than $100 \mu \mathrm{g} \mathrm{ml}^{-1}$ for several weeks after a typical course the drug's success in prophylaxis is understandable (Waddy, 1970) although no longer used.

At concentrations higher than $350 \mu \mathrm{g} \mathrm{ml}^{-1}$, the drug induced significant neurotoxicity (Kaur et al., 2002) and even at lower concentrations neurotoxic effects were evident 
(Bitton et al., 1995). Neuropathy, rash, fatigue, anaemia, hyperglycaemia, hypocalcaemia, coagulopathies, neutropaenia, renal insufficiency and transaminitis are all common. The adverse effects reported with suramin were sufficient for the US Food and Drug Administration to block approval for use in prostate cancer (Kaur et al., 2002), although HAT regimens are short enough to make safety tolerable.

\section{Drugs used in late-stage disease}

Stage 2 of HAT involves progressive breakdown of neurological function, including the alteration in sleep-wake patterns that defines 'sleeping sickness'. In fact, patients do not sleep more than healthy subjects, but the disrupted sleep patterns often manifest themselves in daytime somnolence (Buguet et al., 1993). Alterations in the 'sleep onset rapid eye movement sleep periods' may become a new tool to detect CNS involvement and 2nd stage disease (Buguet et al., 2005). Since the late stage is characterized by the presence of parasites within the cerebral spinal fluid and brain, any drug that is to reach the parasites must first cross the blood-brain barrier or the blood-CSF barrier (Croft, 1999; Enanga et al., 2002; Kennedy, 2006). Many chemicals that show good activity against models of stage 1 disease fail to cure models of stage 2 disease (Jennings et al., 1977; Bouteille et al., 1998) due to the difficulty of getting molecules to cross the bloodbrain barrier.

\section{Melarsoprol}

Background. Melarsoprol (Figure 4), a melaminophenylbased organic arsenical, was introduced in 1949 (Friedheim, 1949). It remains the most widely used drug against latestage HAT in spite of extremely toxic side effects. In the order of $5-10 \%$ of patients taking melarsoprol suffer a reactive encephalopathy (Robertson, 1963; Pepin and Milord, 1994; Blum et al., 2001, 2006); half of these die!

Melarsoprol is the only available compound capable of treating stage 2 T. $b$. rhodesiense disease and the only generally affordable compound to treat stage 2 gambiense disease. It is administered as a $3.6 \%$ solution in propylene glycol and distributed in $5 \mathrm{ml}$ ampoules for intravenous injection. The drug is provided by Sanofi-Aventis free to WHO for distribution and will continue to be provided for at least 5 more years.

Modes of action and resistance mechanisms. It is not known how arsenicals kill trypanosomes. When exposed to melarsoprol, the parasites lyse rapidly (Meshnick et al., 1978). Loss of ATP due to inhibition of glycolysis could underlie lysis although it seems that the cells lyse before ATP supplies are seriously depleted (Vanschaftingen et al., 1987). Arsenic forms stable interactions with thiols including trypanothione (Fairlamb et al., 1989), a key low molecular weight thiol (a bis-glutathionyl-spermidine adduct) found in trypanosomatids but not in mammalian cells (Fairlamb et al., 1985) and lipoic acid (Fairlamb et al., 1992b). Whether these interactions underlie trypanocidal activity is, however, not known.
In several foci, treatment failures have reached levels of 30\% of those treated (Legros et al., 1999; Brun et al., 2001; Moore and Richer, 2001; Stanghellini and Josenando, 2001). Most parasites selected for resistance to melamine-based arsenicals in the laboratory have lost the P2 aminopurine transporter that carries the drug (Carter and Fairlamb, 1993; Barrett and Fairlamb, 1999; Mäser et al., 1999; Stewart et al., 2005) and several parasites isolated from relapse cases in the field are also defective in P2 transport (Mäser et al., 1999; Matovu et al., 2001; Stewart et al., 2005). No significant difference in intrathecal accumulation of drug between successfully treated and relapsing patients was seen (Brun et al., 2001), although the demonstration of parasite resistance in the field has been hampered by difficulties in retrieving T. $b$. gambiense from patients for study. Parasiteamias are generally very low and it is difficult to establish infections in vitro or in rodents. Cryopreservatives like Triladyl (Maina et al., 2006), and African rodent species that are relatively sensitive to $T . b$. gambiense parasites (Buscher et al., 2005; Maina et al., 2007), currently offer hope that collection of samples from the field can be improved.

In vitro, unmetabolized melarsoprol is believed to cross membranes by passive diffusion (Scott et al., 1997). Melarsen oxide, however, enters $T$. brucei principally by the P2 aminopurine transporter (Carter and Fairlamb, 1993) encoded by the tbat1 gene (Mäser et al., 1999). However, trypanosomes from which the tbat1 gene has been removed are only marginally less sensitive to melamine-based arsenicals than are wild-type cells (Matovu et al., 2003), indicating that secondary routes of uptake exist and loss of P2 plus these secondary routes is required for high-level resistance. Low concentrations of pentamidine inhibited a secondary, slow lysis of trypanosomes in a spectrophotometric test (Matovu et al., 2003), prompting suggestions that the HAPT1 (de Koning, 2001a) might be the second route of entry for melarsen oxide. Moreover, the highly pentamidine resistant line derived from the tbat1 gene knockout line was also highly resistant to melarsen oxide and had lost the HAPT1 transporter (Bridges et al., 2007). However, since trypanosomes selected for high-level melarsen resistance retain sensitivity to pentamidine (Fairlamb et al., 1989b), it is clear that more is yet to be learned about all possible routes of uptake of these different classes of drug. Ectopic overexpression of the tbmrpa gene, that encodes a P-glycoprotein type pump, is capable of inducing melarsoprol resistance (Shahi et al., 2002).

Patients are currently treated and then subjected to followup for 2 years. Any recurrence of the disease over that time is considered as a treatment failure. The possibility of identifying trypanosomes that lack the $\mathrm{P} 2$ transporter as being melarsoprol refractory at the time of disease diagnosis has clear benefits. Tests using fluorescent diamidines (for example, furamidine) that enter via the P2 transporter can identify loss of the P2 transporter and these offer potential as a major advance in diagnosis of resistance in the field (Stewart et al., 2005).

Pharmacology. Treatment schedules with melarsoprol show how an understanding of pharmacokinetics can lead to radical improvements in drug regimens. A standardized 
10-day course with $2.2 \mathrm{mg} \mathrm{kg}^{-1}$ given once a day is as effective as older protocols (Burri et al., 2000; Schmid et al., 2004, 2005; Pepin and Mpia, 2006). Melarsoprol was introduced to replace tryparsamide, another arsenical. Tryparsamide administration regimens took into account toxicity associated with drug accumulation in various tissues (Williamson, 1970). It was given over prolonged periods, interspersed with 'rest' periods to enable clearance of drug from tissue deposits. Similar regimens were unnecessarily retained for melarsoprol before implementation of the 10day course.

First studies into melarsoprol's pharmacokinetics employed a bioassay (Hawking, 1962; Burri and Brun, 1992) based on in vitro trypanocidal activity found in various body fluids containing drug. HPLC methods (Bronner et al., 1998) that measure melarsoprol itself failed to identify the key active metabolite, melarsen oxide, which forms rapidly in plasma (96\% clearance within $1 \mathrm{~h})$. Much of the drug is bound to plasma protein. A mean elimination half-life of $3.5 \mathrm{~h}$ for active metabolite was determined (Burri and Brun, 1992; Burri et al., 1993).

Melarsoprol (or melarsen oxide) maximally accumulates across the blood-brain barrier to levels only around $1-2 \%$ of maximum plasma levels (Burri et al., 1993). This is sufficient to clear trypanosomes with typical 'wild-type' sensitivities to the drug. However, a drop in sensitivity of only a few fold could render parasites in the CSF non-susceptible to these levels (Brun et al., 2001; Burri and Keiser, 2001; de Koning, 2001b).

Side effects are severe. Convulsions and other neurological sequelae can precede coma and death in the reactive encephalopathy that afflicts $5-10 \%$ of treated patients. Other adverse events are common. These include pyrexia, headache, pruritis and thrombocytopaenia. Heart failure too has been reported. Co-administration of corticosteroids (for example, prednisolone) yields some protection against the reactive encephalopathy (Pepin et al., 1989a). Thiamine administration too can reportedly ameliorate melarsoprol's adverse events (Pepin and Milord, 1994). It was recently shown (Szyniarowski et al., 2006) that melarsoprol enters mammalian cells via a thiamine transporter, hence coadministration of this vitamin may decrease melarsoprol uptake into mammalian cells but not into trypanosomes. Conjugation of melarsoprol in complexes might improve toxicity by slowing release of the active principle (Gibaud et al., 2002, 2005). Topical application to mouse models of the disease was also successful and lowered toxicity (Jennings et al., 1993; Atouguia et al., 1995). However, in spite of the prospect of deriving improved melarsoprol formulations, the drug's reputation mitigates against taking new arsenical derivatives forward.

\section{Eflornithine}

Background. Eflornithine (Figure 5) or D,L- $\alpha$-difluoromethylornithine (originally marketed as Ornidyl by Marion Merrell Dow) is an analogue of the amino-acid ornithine and acts as an inhibitor of the polyamine biosynthetic enzyme ornithine decarboxylase (ODC) (Bacchi et al., 1980; Phillips et al., 1987; Bacchi and Yarlett, 1993). Eflornithine was first developed as a potential antineoplastic agent; however, it has still not been registered for use in therapy of cancer (Gerner and Meyskens, 2004). The drug has activity against T. b. gambiense, even in the late stage (Burri and Brun, 2003) but against $T . b$. rhodesiense activity is restricted (Iten et al., 1995). The usual regimen involves $100 \mathrm{mg} \mathrm{kg}^{-1}$ body weight at $6 \mathrm{~h}$ intervals (that is, $400 \mathrm{mg} \mathrm{kg}^{-1} \mathrm{day}^{-1}$ ) by intravenous infusion for 14 days. Shorter schedules and oral dosing have so far given lower efficacy.

Mode of action and resistance mechanisms. Eflornithine has similar affinity for both the mammalian and trypanosomal ODCs (Phillips et al., 1988). Its specificity against the parasite may arise because T. $b$. gambiense ODC is degraded and replenished much more slowly than its mammalian counterpart (Ghoda et al., 1990). A pulse of eflornithine thus deprives trypanosomes of net polyamine synthesis for a prolonged period compared with mammalian cells. Lack of activity against rhodesiense parasites may relate to the enzyme being more rapidly turned over in that subspecies (Iten et al., 1997).

Polyamine biosynthesis inhibition is accompanied by an increase in cellular levels of $S$-adenosyl methionine (Yarlett and Bacchi, 1988), which causes inappropriate methylation of proteins, nucleic acids, lipids and other cell components. Trypanothione levels are also diminished after eflornithine treatment (Fairlamb et al., 1987), which might render them more susceptible to oxidative stress and other immunological insult.

A functional immune system is required to kill the growtharrested trypanosomes (Bitonti et al., 1986b), which transform into non-proliferating stumpy forms after exposure to eflornithine. T. brucei lacks polyamine transporters rendering them auxotrophic for polyamines (Fairlamb and Le Quesne, 1997) preventing by-pass of inhibition of polyamine biosynthesis, although the recent demonstration of variability in sensitivity of different T. brucei strains to eflornithine in rodents and a different potential of exogenous polyamines to antagonize eflornithine's activity (Nishimura et al., 2006) could indicate some variability in the parasites' capacity to accumulate polyamines. One $T$. $b$. rhodesiense line selected

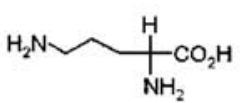

Ornithine

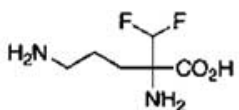

Eflornithine

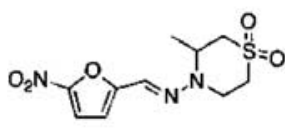

Nifurtimox

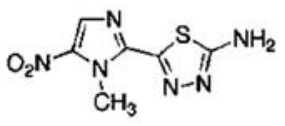

Megazol
Figure 5 Structures of ornithine and eflornithine and some trypanocidal nitroheterocycles. 
for eflornithine resistance showed enhanced capability to import putrescine compared with sensitive lines (Bacchi et al., 1993).

Eflornithine uptake in mammalian cells was reported to involve simple diffusion across the membrane (Erwin and Pegg, 1982). In T. brucei passive diffusion across the plasma membrane in both bloodstream (Bitonti et al., 1986a) and procyclic forms (Bellofatto et al., 1987) was proposed to account for cell entry. However, the compound is rather polar and unlikely to be lipid permeable. In the yeast, Neurospora crassa, uptake is mediated via a cationic aminoacid transporter (Davis et al., 1994). Moreover, another study in procyclic trypanosomes (Phillips and Wang, 1987) showed uptake to be temperature sensitive and to follow MichaelisMenten-type kinetics with an apparent $K_{\mathrm{m}}$ of $244 \mu \mathrm{M}$. Although high concentrations (1 mM; Bitonti et al., 1986a, b) and $20 \mathrm{~mm}$ (Phillips and Wang, 1987) of unlabelled lysine, arginine and ornithine all failed to inhibit uptake, lower doses were not tested and unphysiologically high doses could lead to induction of other routes for eflornithine uptake into the cell, leading to a masking of transportermediated uptake. It is likely that uptake of eflornithine in trypanosomes is carrier mediated. The trypanosome's genome is replete with genes encoding amino-acid transporters (Barrett and Gilbert, 2006) of which one or more could carry eflornithine. Two reports of drug resistance (Bellofatto et al., 1987; Phillips and Wang, 1987) in procyclic forms show that drug uptake is diminished. Thus it seems probable that resistance can relate to loss of, or changes to, eflornithine transport into cells.

Pharmacology. The mean half-life in plasma following intravenous injection of eflornithine is only in the order of $3 \mathrm{~h}$, with $80 \%$ of the drug excreted unchanged in urine after $24 \mathrm{~h}$ (Haegele et al., 1981; Griffin et al., 1987). Little serum protein binding occurs. Accordingly the drug must be given in large doses by prolonged intravenous infusion.

In humans, reported CSF to plasma ratios vary between 0.1 and 0.9 (Milord et al., 1993; Burri and Brun, 2003; NaBangchang et al., 2004) with the ratio towards the lower end of that range more commonly reported. Eflornithine monotherapy apparently fails to cure the stage 2 mouse model, perhaps because the drug fails to cross the blood-brain barrier in rodents (Levin et al., 1983). In combination with suramin, however, cure was possible, but only if mice were kept in a $2 \mathrm{~h}$ light and $4 \mathrm{~h}$ dark regime (Jennings, 1993), which relates to consumption of the drug in drinking water being greatly enhanced (10-15 fold) in darkness (Romijn et al., 1987).

In man, doses beyond $100 \mathrm{mg} \mathrm{kg}^{-1}$ given orally failed to lead to increased appearance of the drug in plasma, which suggests that eflornithine is accumulated by a saturable transporter. It is also probable that a transporter carries the drug across the blood-brain barrier, where the $\mathrm{y}^{+}$system (the main cationic amino-acid transporter in mammals) is the principal cationic amino-acid transporter (O'Kane et al., 2006) and a likely candidate.

$\mathrm{IC}_{50}$ growth inhibitory values for eflornithine of 81$693 \mu \mathrm{M}$ (Zweygarth and Kaminsky, 1991) in vitro are very poor when compared to the other trypanocidal drugs (melarsoprol, suramin and pentamidine all have activity in the nanomolar range). Oral dosing gave average plasma levels of $234-528 \mu \mathrm{M}$ and CSF levels at $22.3-64.7 \mu \mathrm{M}$ in patients receiving 100 or $125 \mathrm{mg} \mathrm{kg}^{-1}$ (Na-Bangchang et al., 2004). In vitro activities do not take into account the role of the immune system in killing trypanosomes (Bitonti et al., 1986b); however, the relative inefficacy of eflornithine, coupled to its poor pharmacokinetic profile, renders the drug far from ideal for use in a tropical setting and it is unlikely that eflornithine would have been pursued had protocols in use today, that begin with efficacy testing against trypanosomes in vitro, been in place when the drug was first explored for use against trypanosomiasis.

Side effects include fever, headache, hypertension, macular rash, peripheral neuropathy and tremor, gastrointestinal problems including diarrhoea (Chappuis et al., 2005b). The incidence and severity of these adverse reactions are considerably lower than similar reactions in melarsoprol therapy, and Médecins sans Frontières (MSF) are currently promoting eflornithine as first-line treatment for stage 2 disease (Chappuis et al., 2005b; Balasegaram et al., 2006), although the risk of resistance emerging must be taken seriously.

\section{Drugs in clinical trials}

\section{Pafuramidine maleate (DB289)}

Background. The only new drug in advanced trials for introduction to use against HAT is pafuramidine maleate (DB289) (Figure 3). This O-methyl amidoxime prodrug (Boykin et al., 1996; Ansede et al., 2004) is converted to the diamidine furamidine (DB75) systemically.

Furamidine was first shown to be trypanocidal in the 1970s (Rane et al., 1976; Das and Boykin, 1977), but it offered little or no benefit over pentamidine and was not pursued at this time (Steck et al., 1982). The efficacy of pentamidine in treatment of PCP, the incidence of which rose sharply as the HIV/AIDS epidemic emerged in the 1980s, led to renewed interest in di-cationic microbicides. Studies into the metabolism of pentamidine (Berger et al., 1990, 1991, 1992; Clement and Jung, 1994) revealed that the positive charges of these molecules, which restrict intestinal absorbtion, could be neutralized by chemical modification. Pentamidine was converted to an amidoxime prodrug (Clement and Raether, 1985; Clement, 2002) with trypanocidal activity when given subcutaneously to mice. However, activity against pneumocystitis was weak (Hall et al., 1998) and furamidine synthesized as its prodrug, pafuramidine maleate (Boykin et al., 1996), was far better in this context. Phase III trials are currently underway for pafuramidine against PCP (Yeates, 2003). Pafuramidine (100 mg twice per day for 5 days) also performed well in clinical trials against malaria (Yeramian et al., 2005). However, a concern that widespread, uncontrolled use of the drug as an antimalarial might enhance the risk for selection of resistance to the drug in trypanosomes has contributed to its being abandoned for malaria. Since many diamidine compounds show superior 
in vitro activity against Plasmodium falciparum, it is hoped that another candidate might emerge for malaria.

Mode of action and resistance mechanisms. As a diamidine it would be anticipated that the modes of action and resistance mechanisms for furamidine may overlap with those of pentamidine and diminazene. Uptake of the compound to high levels (Mathis et al., 2006) occurs principally via the same P2 aminopurine transporter that carries other diamidines into cells (Lanteri et al., 2006). In a 3-day in vitro assay, the activity of furamidine was greatly decreased against the tbat1/P2 knockout cell line and a line selected for resistance to the drug had lost the P2 transporter, through deletion of its gene, confirming this as a main route of uptake (Lanteri et al., 2006). However, these P2 defective cells fail to grow for prolonged periods, even in relatively low concentrations of drug, in vitro. Moreover, the P2 defective cells are only marginally less sensitive than wild type when treated in mice (Lanteri et al., 2006). Thus a secondary route of uptake, albeit minor compared with $\mathrm{P} 2$, plays a significant role in the pharmacology of the drug, and loss of the P2 transporter alone is unlikely to lead to parasites developing resistance.

As furamidine is fluorescent, it has been possible to trace its distribution in cells (Mathis et al., 2006). Within a minute, UV fluorescence is detectable within the DNA containing organelles (nucleus and kinetoplast). By $1 \mathrm{~h}$, the drug becomes visible within organelles believed to be acidocalcisomes (Mathis et al., 2006). After $24 \mathrm{~h}$ exposure to $7.5 \mu \mathrm{M}$ drug, the fluorescence of the kinetoplast has disappeared, as the drug appears to have caused disintegration of this structure (Mathis et al., 2006). Damage to the mitochondrion is also evident, leading to suggestions that the mitochondrion is a target for this drug. In yeast, furamidine (Lanteri et al., 2004) like pentamidine (Ludewig et al., 1994), inhibits the respiratory chain and it also acts as an uncoupler. The mitochondrial inner membrane is also affected by furamidine in trypanosomes (Lanteri et al., unpublished), making it tempting to speculate that mitochondrial disruption relates to activity of this compound.

Pharmacology. In vitro, pafuramidine is over one thousand fold less active against trypanosomes than furamidine (Ansede et al., 2004). In vivo, however, furamidine is active only when given by injection, while pafuramidine is active in an oral formulation. This is because pafuramidine, but not furamidine, crosses intestinal epithelium (Sturk et al., 2004) in quantities sufficient to reach trypanocidal levels in blood. The prodrug is metabolized by cytochrome P450 (CYP4F isoforms in particular) and other metabolic enzymes (Ansede et al., 2005; Saulter et al., 2005; Wang et al., 2006), through demethylation followed by reduction, to the active diamidine. Furamidine does not cross the blood-brain barrier. However a very close relative of furamidine, DB820, which differs by the addition of a single nitrogen into one of the phenyl rings (Figure 3) (Ismail et al., 2003), exerts trypanocidal activity in rodent models of stage 2 disease. The $O$ methyl amidoxime prodrug of DB820, currently coded as DB844, can be administered orally and still lead to the cure of stage 2 mouse model (Ansede et al., 2005), the first orally available compound to exert this effect.
Currently, little is published with regard to the clinical development of pafuramidine for trypanosomiasis. However, studies into metabolism, toxicology and pharmacokinetics in animal models including mouse, rat, vervet monkey and later cynomolgus monkey preceded its entry into phase I clinical trials. These satisfied criteria enabling entry into phase II trials in T. $b$. gambiense patients with stage 1 disease (Yeates, 2003).

An initial open label, non-controlled trial focussed on a site in Angola and one in the Democratic Republic of Congo. Patients were treated with $100 \mathrm{mg}$ of pafuramidine given orally, twice daily for 5 days. Efficacy in that first trial was $83 \%$ cure (93\% of the 30 patients partaking in the trial were cleared of parasites in blood and lymph $24 \mathrm{~h}$ after the final dose. However, after 24 month follow-up a further four patients had relapsed). The regimen was then lengthened to a 10-day treatment for a phase IIb trial. This has been more successful although follow-up must continue until 2 years is complete. A multicentre phase III trial, in which 250 patients will receive DB289 using noninferiority to injected pentamidine as the comparator, is underway.

Some side effects were reported including intermittent fever and pruritis. These were not serious and administration of up to $600 \mathrm{mg}$ in a single dose gave no adverse response.

\section{Diminazene}

Another diamidine, diminazene, is a registered veterinary trypanocide (Kinabo, 1993; Peregrine and Mamman, 1993). Unlicensed use in humans has been successfully attempted (Pepin and Milord, 1994). Dose of drug and time of exposure are important in determining the trypanocidal effect of diminazene. Iten et al. (1997) showed that exposure of trypanosomes to $10 \mu \mathrm{g} \mathrm{ml}^{-1}$ of diminazene for less than 1 min committed the cells to death (although it took several days before the cells died). At $1 \mu \mathrm{g} \mathrm{ml}^{-1}$, the exposure time needed for death rose to $15 \mathrm{~min}$, while at $0.1 \mu \mathrm{g} \mathrm{ml}^{-1}$ cells needed to be exposed for $24 \mathrm{~h}$ before proceeding to a delayed death.

The drug enters trypanosomes via the P2 transporter (Barrett et al., 1995; Ross and Barns, 1996; de Koning et al., 2004; Witola et al., 2004) and tbat1 gene knockout cells (Matovu et al., 2003) are resistant to diminazene. Alternative transporters, such as HAPT1 and LATP1, play a less important role in entry of this compound than they do for pentamidine, although the drug does continue to enter TbAT1/P2 defective cells albeit very slowly (de Koning et al., 2004), and in in vitro assays the P2-deficient cells retain sensitivity to diminazene in the low micromolar range (Matovu et al., 2003).

Pharmacokinetic properties of diminazene deviate widely from pentamidine. For example, the volume of distribution is much lower in animals studied (probably due to less protein binding and tissue retention) (Peregrine and Mamman, 1993). Given that the orally available pafuramidine will complete phase III trials soon, it is this latter compound that is more likely to be approved than diminazene, which will be retained as a veterinary trypanocide. The possibility of selecting parasites that lack the P2 transporter in 
development of diminazene resistance (Barrett et al., 1995) is of concern (de Koning, 2001a, b), especially where T. $b$. rhodesiense is present at significant levels in livestock (Barrett, 2001). The risk of selecting for P2 transporter-defective parasites that might enter humans must be considered before implementing any drug campaigns against veterinary trypanosomiasis.

\begin{abstract}
Nifurtimox
Background. Nifurtimox, marketed as Lampit, is produced by Bayer, provided free to WHO and distributed by MSF for use in trials in HAT therapy or for compassionate use in cases of melarsoprol failure. Success as monotherapy has reportedly been limited (50-80\% cure) against T. brucei gambiense (Janssens and Demuynck, 1977; Pepin et al., 1989b) but its use, particularly in combinations (Moens et al., 1984; Jennings, 1991), is of increasing interest, as reports of treatment failure with arsenical monotherapy rise. Recent trials in combination with eflornithine show great promise (Priotto et al., 2006).
\end{abstract}

Mode of action. Single electron reduction of the nitro group of nifurtimox generates a free radical, which may interact with cellular constituents or generate reduced oxygen metabolites believed to cause parasite death (Docampo and Moreno, 1986; Enanga et al., 2003). With a reduction potential of $-260 \mathrm{mV}$, nifurtimox is relatively easily reduced in many cell types (Viode et al., 1999) but a typical prokaryote-related type 1 nitroreductase identified in the trypanosome's genome is likely to play a role in activation of nifurtimox and other nitroheterocycles (S Wilkinson, London School of Hygiene and Tropical Medicine, personal communication).

Numerous nitroheterocycles have been demonstrated to have potent activity against trypanosomes. Nitrofurazone (a nitrofuran) entered human trials in the mid-twentieth century, but toxicity issues halted its development (Apted, 1970). Several 2-substituted 5-nitroimidazoles (Jennings, 1991) were shown to be efficacious and cured the stage 2 mouse model when co-administered with suramin. The nitroimidazole-thiazole, megazol, too was active when administered with suramin in stage 2 mouse and rat models (Enanga et al., 1998; Darsaud et al., 2004) and also able to cross the blood-brain barrier in significant quantities in a primate model (Enanga et al., 2000). A group of 5-nitro-2furancarbohydrazines were also recently shown to possess substantial trypanocidal activity (Millet et al., 2002).

As host cell toxicity, particularly genotoxicity, has mitigated against development of antimicrobial nitroheterocycles, the possibility of selectively targeting melaminecoupled nitroheterocycles to trypanosomes, via the P2 aminopurine transporter, was investigated (Stewart et al., 2004; Baliani et al., 2005). Several compounds were identified with excellent trypanocidal activity and they appear to enter via routes in addition to P2. The possibility of targeting trypanocides to trypanosomes via transporters has been covered extensively in a recent review (Barrett and Gilbert, 2006).
Pharmacology. Serum levels are reportedly low when nifurtimox is given orally, peaking $1-3 \mathrm{~h}$ after administration of a single $15 \mathrm{mg} \mathrm{kg}^{-1}$ dose, reaching a maximum of around $4 \mu \mathrm{M}$ in healthy subjects (Paulos et al., 1989). Clearance is fast with a plasma elimination half-life of around $3 \mathrm{~h}$ (Paulos et al., 1989). The drug can accumulate across the blood-brain barrier (Burri et al., 2004) to levels around half of those found in plasma. African trypanosomes are not very susceptible to nifurtimox $\left(\mathrm{IC}_{50}\right.$ values of around $5 \mu \mathrm{M}$ compared with $10 \mathrm{nM}$ for melarsen oxide in a typical in vitro assay (Enanga et al., 2003)). This probably explains the drug's limited efficacy as monotherapy.

Toxic effects to the central and peripheral nervous systems have been reported (Castro et al., 2006) and rats given high doses of the drug showed increased risk of cancer (Steinhoff and Grundmann, 1972). Typical regimens used for T. cruzi infections ( $15 \mathrm{mg} \mathrm{kg}^{-1}$ over 60 days) lead to nausea, vomiting and other problems. At $15 \mathrm{mg} \mathrm{kg}^{-1}$, additional adverse affects including polyneuropathy were evident and the gastrointestinal problems more pronounced and more frequent (Pepin et al., 1992).

\section{Combinations}

Combination chemotherapy is becoming the preferred route of administration of antimalarial compounds in the hope of diminishing the probability of selecting for drug-resistant mutants (Kremsner and Krishna, 2004). Treatment failure is also a growing problem in trypanosomiasis therapy (Brun et al., 2001). There are other reasons for using drugs in combination. Synergistic effects can permit the lowering of doses for the combination partners thus reducing adverse effects. Jennings (1993) pioneered work into seeking synergistic effects with trypanocidal drugs in rodent models. Suramin, acts synergistically with many drugs. For example, administration of suramin 15 min before topical administration of melarsoprol led to good cure rates of the stage 2 mouse model. Suramin also altered the volume of distribution and pharmacokinetics of the experimental trypanocide megazol in mice (Enanga et al., 1998), possibly because it inhibits P-glycoprotein pumps (Buxbaum, 1999) that play key roles in maintaining the blood-brain barrier and also in removing xenobiotics through the renal system. Pre-treatment with other agents that induce changes to renal clearance or blood-brain barrier permeability could also influence efficacy of trypanocides in vivo (Croft, 1999).

Recent clinical trials using eflornithine ( $400 \mathrm{mg} \mathrm{kg}^{-1} \mathrm{day}^{-1}$ ) for 7 days in two periods of infusion (rather than 14 days with four infusions) and nifurtimox at $15 \mathrm{mg} \mathrm{kg}^{-1}$ for 10 days have yielded cure rates as high as $98 \%$ (Priotto et al., 2006). Other combinations (melarsoprol and eflornithine or melarsoprol and nifurtimox) were considered too toxic to pursue (Priotto et al., 2006). Nifurtimox exerts its activity through induction of oxidative stress (Docampo and Moreno, 1986; Enanga et al., 2003) while eflornithine diminishes levels of trypanothione, a key metabolite used in protecting against oxidative stress, thus it is possible that these drugs synergize at the level of parasite killing.

Since melarsoprol treatment failure rates have been increasing, and because resistance to eflornithine is relatively 
easy to select in the laboratory (Bellofatto et al., 1987; Phillips and Wang, 1987; Bacchi et al., 1993), in the absence of alternative drugs every effort should be taken to delay the onset of resistance to eflornithine in the field. The use of a nifurtimox-eflornithine combination presently offers promise in this regard.

\section{Phamacological re-engagement with HAT}

By the end of the twentieth century it had been widely accepted that industrial input to neglected diseases like HAT was not viable on purely commercial grounds. For some diseases, like malaria and tuberculosis, with prevalences greatly in excess of HAT, public-private partnerships, the Medicines for Malaria Venture (http://www.mmv.org) and The Global Alliance for TB Drug Development (TB Alliance) (http://new.tballiance.org/home/home-live.php), were founded in 1999 and 2000, respectively.

For HAT, however, the situation reached a low point at the turn of the Century (Barrett, 1999). The prevalence of the disease had reached alarming levels. Treatment failures with melarsoprol were reported in several foci and Aventis, the manufacturer of that drug, found themselves confronted with the dilemma of whether to continue producing, at a loss, one of the most toxic compounds known to the pharmacopoeia, or to drop production leaving patients to die. MSF and other non-governmental organizations were establishing centres in many African countries to deal with the crisis and drugs for HAT soon made it to the forefront of MSF's campaign on 'Access for Essential Medicines' (Pécoul et al., 1999). WHO were engaged in an apparently fruitless quest to find a manufacturer for eflornithine after Hoechst Marion Roussel (which was later incorporated into Aventis) had abandoned production in the 1990s.

Then, in 2000, an extraordinary event occurred. Gillette launched eflornithine, made by Bristol-Myers Squibb, as a topical formulation under the trade name Vaniqa, to suppress the growth of unwanted facial hair. It was at this point that Aventis, now Sanofi-Aventis, were persuaded to produce the drug free for WHO to distribute to national programmes involved in HAT therapy. Aventis also agreed to provide pentamidine and melarsoprol gratis for an initial period of 5 years (2001-2006) and Bayer joined in by donating suramin and nifurtimox too. Aventis have recently extended their support for 5 more years (until 2011), and surveillance and research were also stepped up under the WHO-Aventis deal. In addition to the role of WHO other initiatives are playing a role.

In 1999, The Bill and Melinda Gates Foundation was established and has set about funding, to unprecedented levels, initiatives in global health and education. With an endowment fund of $\$ 31.7$ billion the Foundation has transformed the environment with regard to funding in several tropical diseases. Late in 2000, the Foundation started funding a group of researchers under the leadership of the University of North Carolina at Chapel Hill (UNC) to develop pafuramidine for HAT. As discussed earlier, there is a genuine hope that the drug will successfully complete trials within 2 years and plans are already being drawn up for its manufacture and distribution. In addition to the develop- ment of pafuramidine, the UNC-led consortium also received funds to seek new drugs for visceral leishmaniasis and the consortium was refunded in 2006 to continue searching for new drugs for late-stage HAT and visceral leishmaniasis, as well as to take pafuramidine through clinical trials. Other initiatives are also underway. The Special Programme for Research and Training in Tropical Diseases of WHO (WHO/TDR) has long fought for new drugs for HAT and other tropical diseases. Following consultation initiated through MSF's 'Access Campaign' (Trouiller et al., 2002), the Drugs for Neglected Diseases initiative (DNDi) (http:www.dndi/org), a Public Private Partnership, was founded in 2003, to discover and develop new drugs to treat trypanosomatid diseases (HAT, Chagas disease and leishmaniases). The UK's Wellcome Trust has remained a major player in the field of trypanosomiasis research. They provided much of the funding required to sequence the trypanosome's genome (Berriman et al., 2005). With the genome known, every potential drug target within the trypanosome is now accessible. Gene knockout (Barrett et al., 1999) and RNA interference can both be used to provide evidence as to whether genes, and the proteins they encode are essential and thus validated drug targets. A natural progression has been for the Wellcome Trust to establish a screening centre at the University of Dundee, where a library of chemicals (containing an initial set of 62000 compounds, selected for lead drug-like criteria) is being screened systematically for activity against validated targets (http:// www.drugdiscovery.dundee.ac.uk). High-throughput screening is also underway at the Sandler Centre at the University of California, San Franciso (http://www.ucsf.edu/mckerrow/ slide.html).

The in vitro model system to test trypanocidal efficacy in operation at a number of centres, the largest of which were originally supported by WHO/TDR (http://www.who.int/tdr/), allows rapid screening of tens of thousands of compounds for trypanocidal activity. These centres offer pharmaceutical companies an opportunity to re-engage with diseases like HAT without having to set up in-house facilities. Pfizer Animal Health, for example, has recently initiated a screening programme with their compound libraries in collaboration with WHO/TDR against a range of tropical diseases, including HAT. DNDi has linked up with agencies holding natural product libraries to enter similar screens. DNDi is also pursuing other lead compounds by bringing together groups of investigators in consortia to proceed through the development process. Potent trypanocides discovered in these screens can then enter rodent models of stages 1 and 2 disease to test in vivo efficacy.

The surge in activity in research into new drugs for HAT should see the emergence of numerous lead compounds over the next few years. A bottleneck in drug development, however, is likely to appear at this point. Committed chemists and pharmacologists must join the venture to optimize leads. The narrowest bottleneck will, however, involve taking compounds into clinical trials.

In addition to the advancement of pafuramidine through phase III trials, the UNC-led consortium is funded to seek new agents for stage 1 and, especially, stage 2 HAT. In addition to in-house chemistry efforts, novel compounds 
emerging from other screening programmes will be considered by the UNC group to take through the latter stages of development, drawing on the experience gained in the development of pafuramidine. The development of pafuramidine provides a good model on the kinds of interaction needed to take a compound through the whole-development process. A tightly knit, multidisciplinary, multinational consortium, involving academic and industrial input to cover all aspects of drug development has been necessary. The project was founded on the premise that diamidines are highly trypanocidal and that chemical modification could allow changes that effect efficacy and pharmacokinetics in a manner to optimize use. The consortium involves chemists who can produce new compounds that are screened in assays for trypanocidal activity and for in vivo efficacy (and against drug-resistant trypanosomes). Uptake into trypanosomes and their ability to bind putative targets is also tested in a systematic fashion. Iterative syntheses based on structureactivity relationships are possible. Hit compounds can be tested for efficacy and pharmacokinetic properties in rodent and simian models, in an academic setting, with the best compounds then sent for GLP testing in an industrial setting.

For pafuramidine itself, its potential use against PCP meant that phase I clinical trials had already been completed by the time the UNC-led consortium commenced their effort on trypanosomiasis. This enabled its rapid introduction into phase II trials against HAT patients. Fortunately, investigators from the Swiss Tropical Institute had recently been engaged with a series of centres in Africa to test the new melarsoprol short course (Burri et al., 2000), thus trials in these centres, under conditions that came as close as is possible, in this environment, to Good Clinical Practise became a possibility. Clinical trials within HAT affected areas offer great challenges. For example, in conditions where electricity supplies are often absent, facilities enabling constant temperature storage of compounds become impossible. Biochemical and physiological tests considered routine in a hospital in the west cannot be conducted and so on. The pafuramidine project, having received appropriate funding for clinical trials and also having garnered support from national programmes and WHO, has managed to proceed remarkably smoothly.

The number of people capable of conducting such trials is limited. Moreover, the recent downturn in the incidence of HAT (Anonymous, 2006; Barrett, 2006), coupled to the requirement for strict exclusion criteria to reach objective conclusions from trials, offers a very major problem. Patients located in the vicinity of the few centres capable of conducting satisfactory clinical trials are presently in short supply. Logistical problems restrict the ability to reach other areas and to recruit patients into trials relatively far from their homes. Diagnostics, active case finding and the establishment of new facilities in remote areas where the disease is most prevalent will be required to ensure that meaningful clinical trials are possible once compounds begin to emerge over the next 2-10 years.

The problem has been recognized and the Bill and Melinda Gates Foundation has recently funded the Foundation for Innovative New Diagnostics (http://www.finddiagnostics. org) and WHO to seek new diagnostics. With a view to ensuring that any new drugs can be targeted most efficiently to those who need them, the UNC-led consortium has also initiated efforts to identify the precise extent and distribution of HAT, building on statistics collected by the WHO over many years. DNDi along with other key agencies, including WHO, has been formulating a 'platform for clinical trials' to standardize and coordinate efforts.

Unprecedented activity in the area of drug discovery for HAT is underway, plans to help products through development bottlenecks are being put in place and there is currently, for the first time in a generation, great optimism that novel drugs for HAT will emerge over the next decade.

\section{Conclusions}

HAT has become a cause celèbre among those concerned with the economic factors that have led to diseases of the world's poorest populations becoming neglected in terms of new drug development. The agents that are currently available as anti-trypanosomals are generally unsatisfactory due to a combination of their low efficacy, dangerous side effects and difficulty in administration. In the twenty-first century, however, the situation is changing. Increased knowledge about the trypanosomal genome has already led to the identification of novel drug targets. This development has occurred in parallel with the emergence of funding agencies committed to the elimination of sleeping sickness through coherent and integrated research projects. There is now unprecedented optimism that new drugs active against both stage 1 and stage 2 of the disease will emerge over the next decade.

\section{Acknowledgements}

We are grateful to the Bill and Melinda Gates Foundation for funding a Consortium aiming to develop new drugs for human African trypanosomiasis and visceral leishmaniasis.

\section{Conflict of interest}

The authors are part of the Bill and Melinda Gates Foundation funded Consortium involved in the development of pafuramidine maleate and other new drugs for human African trypanosomiasis and leishmaniasis.

\section{References}

Allsopp R (2001). Options for vector control against trypanosomiasis in Africa. Trends Parasitol 17: 15-19.

Anonymous (2006). Human African trypanosomiasis (sleeping sickness): epidemiological update. Wkly Epidemiol Rec 81: 71-80.

Ansede JH, Anbazhagan M, Brun R, Easterbrook JD, Hall JE, Boykin DW (2004). O-alkoxyamidine prodrugs of furamidine: in vitro transport and microsomal metabolism as indicators of in vivo efficacy in a mouse model of Trypanosoma brucei rhodesiense infection. J Med Chem 47: 4335-4338. 
Ansede JH, Voyksner RD, Ismail MA, Boykin DW, Tidwell RR, Hall JE (2005). In vitro metabolism of an orally active $O$-methyl amidoxime prodrug for the treatment of CNS trypanosomiasis. Xenobiotica 35: 211-226.

Apted FIC (1970). Treatment of human trypanosomiasis (Chapter 36). In: Mulligan HW (ed). The African Trypanosomiases. Allen \& Unwin Ltd: London, pp 684-710.

Atouguia JM, Jennings FW, Murray M (1995). Successful treatment of experimental murine Trypanosoma brucei infection with topical melarsoprol gel. Trans $R$ Soc Trop Med Hyg 89: 531-533.

Bacchi CJ, Garofalo J, Ciminelli M, Rattendi D, Goldberg B, McCann PP et al. (1993). Resistance to DL-alpha-difluoromethylornithine by clinical isolates of Trypanosoma brucei rhodesiense. Role of $S$-adenosylmethionine. Biochem Pharmacol 46: 471-481.

Bacchi CJ, Nathan HC, Hutner SH (1980). Polyamine metabolism a potential therapeutic target in trypanosomes. Science 210: 332-334.

Bacchi CJ, Yarlett N (1993). Effects of antagonists of polyamine metabolism on African trypanosomes. Acta Trop 54: 225-236.

Balasegaram M, Harris S, Checchi F, Ghorashian S, Hamel C, Karunakara U (2006). Melarsoprol versus eflornithine for treating late-stage Gambian trypanosomiasis in the Republic of the Congo. Bull World Health Organ 84: 783-791.

Baliani A, Bueno GJ, Stewart ML, Yardley V, Brun R, Barrett MP et al. (2005). Design and synthesis of a series of melamine-based nitroheterocycles with activity against trypanosomatid parasites. J Med Chem 48: 5570-5579.

Barrett MP (1999). The fall and rise of sleeping sickness. Lancet 353: $1113-1114$.

Barrett MP (2000). Problems for the chemotherapy of human African trypanosomiasis. Curr Opin Infect Dis 13: 647-651.

Barrett MP (2001). Veterinary link to drug resistance in human African trypanosomiasis? Lancet 358: 603-604.

Barrett MP (2003). Drug resistance in sleeping sickness. WHO expert committee on African trypanosomiasis (sleeping sickness). pp 96-111.

Barrett MP (2006). The rise and fall of sleeping sickness. Lancet 367: $1377-1378$

Barrett MP, Burchmore RJS, Stich A, Lazzari JO, Frasch AC, Cazzulo JJ et al. (2003). The trypanosomiases. Lancet 362: 1469-1480.

Barrett MP, Fairlamb AH (1999). The biochemical basis of arsenicaldiamidine crossresistance in African trypanosomes. Parasitol Today 15: 136-140.

Barrett MP, Gilbert IH (2006). Targeting of toxic compounds to the trypanosome's interior. Adv Parasitol 63: 126-183.

Barrett MP, Mottram JC, Coombs GH (1999). Recent advances in identifying and validating drug targets in trypanosomes and leishmanias. Trends Microbiol 7: 82-88.

Barrett MP, Zhang ZQ, Denise H, Giroud C, Baltz T (1995). A diamidine-resistant Trypanosoma equiperdum clone contains a P2 purine transporter with reduced substrate affinity. Mol Biochem Parasitol 73: 223-229.

Basselin M, Denise H, Coombs GH, Barrett MP (2002). Resistance to pentamidine in Leishmania mexicana involves exclusion of the drug from the mitochondrion. Antimicrob Agents Chemother 46: 3731-3738.

Basselin M, Robert-Gero M (1998). Alterations in membrane fluidity, lipid metabolism, mitochondrial activity, and lipophosphoglycan expression in pentamidine-resistant leishmania. Parasitol Res 84: 78-83.

Bastin P, Stephan A, Raper J, SaintRemy JM, Opperdoes FR, Courtoy PJ (1996). An M(r) 145000 low-density lipoprotein (LDL)-binding protein is conserved throughout the Kinetoplastida order. Mol Biochem Parasitol 76: 43-56.

Bellofatto V, Fairlamb AH, Henderson GB, Cross GAM (1987). Biochemical-changes associated with alpha-difluoromethylornithine uptake and resistance in Trypanosoma brucei. Mol Biochem Parasitol 25: 227-238.

Berger BJ, Carter NS, Fairlamb AH (1993). Polyamine and pentamidine metabolism in African trypanosomes. Acta Trop 54: 215-224.

Berger BJ, Carter NS, Fairlamb AH (1995). Characterization of pentamidine-resistant Trypanosoma brucei brucei. Mol Biochem Parasitol 69: 289-298.
Berger BJ, Lombardy RJ, Marbury GD, Bell CA, Dykstra CC, Hall JE et al. (1990). Metabolic $N$-hydroxylation of pentamidine in vitro. Antimicrob Agents Chemother 34: 1678-1684

Berger BJ, Naiman NA, Hall JE, Peggins J, Brewer TG, Tidwell RR (1992). Primary and secondary metabolism of pentamidine by rats. Antimicrob Agents Chemother 36: 1825-1831.

Berger BJ, Reddy VV, Le ST, Lombardy RJ, Hall JE, Tidwell RR (1991). Hydroxylation of pentamidine by rat liver microsomes. I Pharmacol Exp Ther 256: 883-889.

Berriman M, Ghedin E, Hertz-Fowler C, Blandin G, Renauld H, Bartholomeu DC et al. (2005). The genome of the African trypanosome Trypanosoma brucei. Science 309: 416-422.

Besteiro S, Barrett MP, Rivière L, Bringaud F (2005). Energy generation in insect stages of Trypanosoma brucei: metabolism in flux. Trends Parasitol 21: 185-191.

Bitonti AJ, Bacchi CJ, McCann PP, Sjoerdsma A (1986a). Uptake of alpha-difluoromethylornithine by Trypanosoma brucei brucei. Biochem Pharmacol 35: 351-354.

Bitonti AJ, Mccann PP, Sjoerdsma A (1986b). Necessity of antibodyresponse in the treatment of African trypanosomiasis with alpha-difluoromethylornithine. Biochem Pharmacol 35: 331-334.

Bitton RJ, Figg WD, Venzon DJ, Dalakas MC, Bowden C, Headlee D et al. (1995). Pharmacologic variables associated with the development of neurologic toxicity in patients treated with suramin. J Clin Oncol 13: 2223-2229.

Blum J, Nkunku S, Burri C (2001). Clinical description of encephalopathic syndromes and risk factors for their occurrence and outcome during melarsoprol treatment of human African trypanosomiasis. Trop Med Int Health 6: 390-400.

Blum J, Schmid C, Burri C (2006). Clinical aspects of 2541 patients with second stage human African trypanosomiasis. Acta Trop 97: $55-64$.

Bouteille B, Millet P, Enanga B, Mezui Me J, Keita M, Jauberteau MO et al. (1998). Human African trypanosomiasis, contributions of experimental models. Bull Soc Pathol Exot 91: 127-132.

Boykin DW, Kumar A, Hall JE, Bender BC, Tidwell RR (1996). AntiPneumocystis activity of bis-amidoximes and bis-O-alkylamidoxime prodrugs. Bioorg Med Chem Lett 6: 3017-3020.

Bray PG, Barrett MP, Ward SA, de Koning HP (2003). Pentamidine uptake and resistance in pathogenic protozoa: past, present and future. Trends Parasitol 19: 232-239.

Bridges DJ, Gould MK, Nerima B, Maeser P, Burchmore RJ, de Koning HP (2007). Loss of the high affinity pentamidine transporter is responsible for high levels of cross-resistance between arsenical and diamidine drugs in African trypanosomes. Mol Pharmacol 71: 1098-1108.

Bronner U, Brun R, Doua F, Ericsson O, Burri C, Keiser J et al. (1998). Discrepancy in plasma melarsoprol concentrations between HPLC and bioassay methods in patients with $T$. gambiense sleeping sickness indicates that melarsoprol is metabolized. Trop Med Int Health 3: 913-917.

Bronner U, Doua F, Ericsson O, Gustafsson LL, Miezan TW, Rais M et al. (1991). Pentamidine concentrations in plasma, whole blood and cerebrospinal fluid during treatment of Trypanosoma gambiense infection in Cote d'Ivoire. Trans $R$ Soc Trop Med Hyg 85: 608-611.

Brun R, Balmer O (2006). New developments in human African trypanosomiasis. Curr Opin Infect Dis 19: 415-420.

Brun R, Schumacher R, Schmid C, Kunz C, Burri C (2001). The phenomenon of treatment failures in human African trypanosomiasis. Trop Med Intl Health 6: 906-914.

Buguet A, Bert J, Tapie P, Tabaraud F, Doua F, Lonsdorfer J et al. (1993). Sleep-wake cycle in human African trypanosomiasis. J Clin Neurophysiol 10: 190-196.

Buguet A, Bisser S, Josenando T, Chapotot F, Cespuglio R (2005). Sleep structure: a new diagnostic tool for stage determination in sleeping sickness. Acta Trop 93: 107-117.

Burri C, Baltz T, Giroud C, Doua F, Welker HA, Brun R (1993). Pharmacokinetic properties of the trypanocidal drug melarsoprol. Chemotherapy 39: 225-234.

Burri C, Brun R (1992). An in vitro bioassay for quantification of melarsoprol in serum and cerebrospinal fluid. Trop Med Parasitol 43: $223-225$. 
Burri C, Brun R (2003). Eflornithine for the treatment of human African trypanosomiasis. Parasitology Res 90: S49-S52.

Burri C, Keiser J (2001). Pharmacokinetic investigations in patients from northern Angola refractory to melarsoprol treatment. Trop Med Int Health 6: 412-420.

Burri C, Nkunku S, Merolle A, Smith T, Blum J, Brun R (2000). Efficacy of new, concise schedule for melarsoprol in treatment of sleeping sickness caused by Trypanosoma brucei gambiense: a randomised trial. Lancet 355: 1419-1425.

Burri C, Stich A, Brun R (2004). Current chemotherpay of human African trypanosomiasis. In: Maudlin I, Holmes PH, Miles MA (eds). The Trypanosomiases. CABI: Oxford, pp 403-420.

Buscher P, Bin Shamamba SK, Ngoyi DM, Pyana P, Baelmans R, Magnus E et al. (2005). Susceptibility of Grammomys surdaster thicket rats to Trypanosoma brucei gambiense infection. Trop Med Int Health 10: 850-855.

Buxbaum E (1999). Co-operative binding sites for transported substrates in the multiple drug resistance transporter Mdr1. Eur J Biochem 265: 64-70.

Carter NS, Berger BJ, Fairlamb AH (1995). Uptake of diamidine drugs by the P2 nucleoside transporter in melarsen-sensitive and -resistant Trypanosoma brucei brucei. J Biol Chem 270: 28153-28157.

Carter NS, Fairlamb AH (1993). Arsenical-resistant trypanosomes lack an unusual adenosine transporter. Nature 361: 173-176.

Castro JA, de Mecca MM, Bartel LC (2006). Toxic side effects of drugs used to treat Chagas' disease (American trypanosomiasis). Hum Exp Toxicol 25: 471-479.

Chappuis F, Loutan L, Simarro P, Lejon V, Buscher P (2005a). Options for field diagnosis of human African trypanosomiasis. Clin Microbiol Rev 18: 133-146.

Chappuis F, Udayraj N, Stietenroth K, Meussen A, Bovier PA (2005b). Eflornithine is safer than melarsoprol for the treatment of secondstage Trypanosoma brucei gambiense human African trypanosomiasis. Clin Infect Dis 41: 748-751.

Clement B (2002). Reduction of $N$-hydroxylated compounds: amidoximes ( $N$-hydroxyamidines) as pro-drugs of amidines. Drug Metab Rev 34: 565-579.

Clement B, Jung F (1994). N-hydroxylation of the antiprotozoal drug pentamidine catalyzed by rabbit liver cytochrome P-450 2C3 or human liver microsomes, microsomal retroreduction, and further oxidative transformation of the formed amidoximes. Possible relationship to the biological oxidation of arginine to NG-hydroxyarginine, citrulline, and nitric oxide. Drug Metab Dispos 22: 486-497.

Clement B, Raether W (1985). Amidoximes of pentamidine: synthesis, trypanocidal and leishmanicidal activity. Arzneimittelforschung 35: 1009-1014.

Collins JM, Klecker Jr RW, Yarchoan R, Lane HC, Fauci AS, Redfield RR et al. (1986). Clinical pharmacokinetics of suramin in patients with HTLV-III/LAV infection. J Clin Pharmacol 26: 22-26.

Conte JE (1991). Pharmacokinetics of intravenous pentamidine in patients with normal renal function or receiving haemodialysis. J Infect Dis 163: 169-175.

Coppens I, Courtoy PJ (2000). The adaptative mechanisms of Trypanosoma brucei for sterol homeostasis in its different life-cycle environments. Annu Rev Microbiol 54: 129-156.

Croft SL (1999). Pharmacological approaches to antitrypanosomal chemotherapy. Mem Inst Oswaldo Cruz 94: 215-220.

Croft SL, Brazil RP (1982). Effect of pentamidine isethionate on the ultrastructure and morphology of Leishmania mexicana amazonensis in vitro. Ann Trop Med Parasitol 76: 37-43.

Damper D, Patton CL (1976a). Pentamidine transport and sensitivity in brucei-group trypanosomes. J Protozool 23: 349-356.

Damper D, Patton CL (1976b). Pentamidine transport in Trypanosoma brucei - kinetics and specificity. Biochem Pharmacol 25: 271-276.

Darsaud A, Chevrier C, Bourdon L, Dumas M, Guguet A, Bouteille B (2004). Megazol combined with suramin improves a new diagnosis index of the early meningo-encephalitic phase of experimental African trypanosomiasis. Trop Med Intern Health 9: 83-91.

Das BP, Boykin DW (1977). Synthesis and antiprotozoal activity of 2,5-bis(4-guanylphenyl)furans. J Med Chem 20: 531-536.

Davis RH, Lieu P, Ristow JL (1994). Neurospora mutants affecting polyamine-dependent processes and basic-amino-acid transport mutants resistant to the polyamine inhibitor, alpha-difluoromethylornithine. Genetics 138: 649-655.

de Koning HP (2001a). Uptake of pentamidine in Trypanosoma brucei brucei is mediated by three distinct transporters: implications for cross-resistance with arsenicals. Mol Pharmacol 59: 586-592.

de Koning HP (2001b). Transporters in African trypanosomes: role in drug action and resistance. Int J Parasitol 31: 512-522.

de Koning HP, Anderson LF, Stewart ML, Burchmore RJS, Wallace LJM, Barrett MP (2004). The trypanocide diminazene aceturate is accumulated predominantly through the TbAT1 purine transporter: additional insights on diamidine resistance in African trypanosomes. Antimicrob Agents Chemother 48: 1515-1519.

Denise H, Barrett MP (2001). Uptake and mode of action of drugs used against sleeping sickness. Biochem Pharmacol 61: 1-5.

Docampo R, Moreno SNJ (1986). Free-radical metabolism of antiparasitic agents. Fed Proc 45: 2471-2476.

Doua F, Miezan TW, Singaro JRS, Yapo FB, Baltz T (1996). The efficacy of pentamidine in the treatment of early-late stage Trypanosoma brucei gambiense trypanosomiasis. Am J Trop Med Hyg 55: 586-588.

Doua F, Yapo FB (1993). Human trypanosomiasis in the Ivory Coast - therapy and problems. Acta Tropica 54: 163-168.

Drews J (2004). Paul Ehrlich: Magister Mundi. Nat Rev Drug Discov 3 : 797-801.

Eisenberger MA, Reyno L (1994). Suramin. Cancer Treat Rev 20: 259-273.

El Rayah IE, Kaminsky R, Schmid C, El Malik KH (1999). Drug resistance in Sudanese Trypanosoma evansi. Vet Parasitol 80: 281-287.

Enanga B, Burchmore RJ, Stewart ML, Barrett MP (2002). Sleeping sickness and the brain. Cell Mol Life Sci 59: 845-858.

Enanga B, Keita M, Chauvière G, Dumas M, Bouteille B (1998). Megazol combined with suramin: a chemotherapy regimen which reversed the CNS pathology in a model of human African trypanosomiasis in mice. Trop Med Int Health 3: 736-741.

Enanga B, Ariyanayagam MR, Stewart ML, Barrett MP (2003). Activity of megazol, a trypanocidal nitroimidazole, is associated with DNA damage. Antimicrob Agents Chemother 47: 3368-3370.

Enanga B, Ndong JM, Boudra H, Debrauwer L, Dubreuil G, Bouteille B et al. (2000). Pharmacokinetics, metabolism and excretion of megazol in a Trypanosoma brucei gambiense primate model of human African trypanosomiasis. Preliminary study. Arzneimittelforschung 50: 158-162.

Engstler M, Thilo L, Weise F, Grunfelder CG, Schwarz H, Boshart M et al. (2004). Kinetics of endocytosis and recycling of the GPIanchored variant surface glycoprotein in Trypanosoma brucei. J Cell Sci 117: 1105-1115.

Erwin BG, Pegg AE (1982). Uptake of alpha-difluoromethylornithine by mouse fibroblasts. Biochem Pharmacol 31: 2820-2823.

Fairlamb AH (2003). Chemotherapy of human African trypanosomiasis: current and future prospects. Trends Parasitol 19: 488-494.

Fairlamb AH, Blackburn P, Ulrich P, Chait BT, Cerami A (1985). Trypanothione - a novel bis(glutathionyl)spermidine cofactor for glutathione-reductase in trypanosomatids. Science 227: 1485-1487.

Fairlamb AH, Bowman IBR (1977). Trypanosoma brucei - suramin and other trypanocidal compounds effects on Sn-glycerol-3-phosphate oxidase. Exp Parasitol 43: 353-361.

Fairlamb AH, Bowman IBR (1980). Uptake of the trypanocidal drug suramin by bloodstream forms of Trypanosoma brucei and its effect on respiration and growth-rate in vivo. Mol Biochem Parasitol 1: 315-333.

Fairlamb AH, Carter NS, Cunningham M, Smith K (1992a). Characterization of melarsen-resistant Trypanosoma brucei brucei with respect to cross-resistance to other drugs and trypanothione metabolism. Mol Biochem Parasitol 53: 213-222.

Fairlamb AH, Henderson GB, Bacchi CJ, Cerami A (1987). In vivo effects of difluoromethylornithine on trypanothione and polyamine levels in blood-stream forms of Trypanosoma brucei. Mol Biochem Parasitol 24: 185-191.

Fairlamb AH, Henderson GB, Cerami A (1989). Trypanothione is the primary target for arsenical drugs against African trypanosomes. Proc Natl Acad Sci USA 86: 2607-2611.

Fairlamb AH, Le Quesne SA (1997). Polyamine metabolism in trypanosomes. In: Hide G, Mottram JC, Coombs GH, Holmes PH 
(eds). Trypanosomiasis and Leishmaniasis. $\mathrm{CAB}$ International: Oxford, pp 149-161.

Fairlamb AH, Smith K, Hunter KJ (1992b). The interaction of arsenical drugs with dihydrolipoamide and dihydrolipoamide dehydrogenase from arsenical resistant and sensitive strains of Trypanosoma brucei brucei. Mol Biochem Parasitol 53: 223-231.

Fevre EM, Picozzi K, Fyfe J, Waiswa C, Odiit M, Coleman PG et al. (2005). A burgeoning epidemic of sleeping sickness in Uganda. Lancet 366: 745-747.

Friedheim EAH (1949). MelB in the treatment of human trypanosomiasis. Am J Trop Med Hyg 29: 173-180.

Frommel TO, Balber AE (1987). Flow cytofluorometric analysis of drug accumulation by multidrug-resistant Trypanosoma brucei brucei and T.b. rhodesiense. Mol Biochem Parasitol 26: 183-191.

Gerner EW, Meyskens Jr FL (2004). Polyamines and cancer: old molecules, new understanding. Nat Rev Cancer 4: 781-792.

Ghoda L, Phillips MA, Bass KE, Wang CC, Coffino P (1990). Trypanosome ornithine decarboxylase is stable because it lacks sequences found in the carboxyl terminus of the mouse enzyme which target the latter for intracellular degradation. J Biol Chem 265: 11823-11826.

Gibaud S, Gaia A, Astier A (2002). Slow-release melarsoprol microparticles. Int J Pharmacol 243: 161-166.

Gibaud S, Zirar SB, Mutzenhardt P, Fries I, Astier A (2005). Melarsoprol-cyclodextrin inclusion complexes. Int I Pharmacol 306: 107-121.

Green HP, Del Pilar Molina Portela M, St Jean EN, Lugli EB, Raper J (2003). Evidence for a Trypanosoma brucei lipoprotein scavenger receptor. J Biol Chem 278: 422-427.

Griffin CA, Slavik M, Chien SC, Hermann J, Thompson G, Blanc O et al. (1987). Phase I trial and pharmacokinetic study of intravenous and oral alpha- difluoromethylornithine. Invest New Drugs 5: 177-186.

Haegele KD, Alken RG, Grove J, Schechter PJ, Koch-Weser J (1981). Kinetics of alpha-difluoromethylornithine: an irreversible inhibitor of ornithine decarboxylase. Clin Pharmacol Therap 30: 210-217.

Hall JE, Kerrigan JE, Ramachandran K, Bender BC, Stanko JP, Jones SK et al. (1998). Anti-Pneumocystis activities of aromatic diamidoxime prodrugs. Antimicrob Agents Chemother 42: 666-674.

Hanau S, Rippa M, Bertelli M, Dallocchio F, Barrett MP (1996). 6-Phosphogluconate dehydrogenase from Trypanosoma brucei. Kinetic analysis and inhibition by trypanocidal drugs. Eur $J$ Biochem 240: 592-599.

Hawking F (1962). Estimation of the concentration of melarsoprol (Mel B) and Mel W in biological fluids by bioassay with trypanosomes in vitro. Trans $R$ Soc Trop Med Hyg 56: 354-363.

Hawking FJ, Smiles SJ (1941). The distribution of 4:4'-diamidino stilbene in trypanosomes and mice as shown by fluorescence. Ann Trop Med Parasitol 35: 45-50.

Hentzer B, Kobayasi T (1977). The ultrastructural changes of Leishmania tropica after treatment with pentamidine. Ann Trop Med Parasitol 71: 157-166.

Ismail MA, Brun R, Easterbrook JD, Tanious FA, Wilson WD, Boykin DW (2003). Synthesis and antiprotozoal activity of aza-analogues of furamidine. J Med Chem 46: 4761-4769.

Iten M, Matovu E, Brun R, Kaminsky R (1995). Innate lack of susceptibility of Ugandan Trypanosoma brucei rhodesiense to D,L-alpha-difluoromethylornithine (DFMO). Trop Med Parasitol 46: $190-194$

Iten M, Mett H, Evans A, Enyaru JC, Brun R, Kaminsky R (1997). Alterations in ornithine decarboxylase characteristics account for tolerance of Trypanosoma brucei rhodesiense to D,L-alphadifluoromethylornithine. Antimicrob Agents Chemother 41: 1922-1925.

Janssens PG, Demuynck A (1977). Clinical-trials with nifurtimox in African trypanosomiasis. Ann Soc Belg Med Trop 57: 475-480.

Jennings FW (1991). Chemotherapy of CNS-trypanosomiasis - the combined use of the arsenicals and nitrocompounds. Trop Med Parasitol 42: 139-142.

Jennings FW (1993). Combination chemotherapy of CNS trypanosomiasis. Acta Trop 54: 205-213.

Jennings FW (1995). Suramin treatment of experimental Trypanosoma brucei infection of the central nervous system. Trans $R$ Soc Trop Med Hyg 89: 677.
Jennings FW, Atouguia JM, Murray M (1993). Topical melarsoprol for trypanosomiasis. Lancet 341: 1341-1342.

Jennings FW, Whitelaw DD, Urquhart GM (1977). The relationship between duration of infection with Trypanosoma brucei in mice and the efficacy of chemotherapy. Parasitology 75: 143-153.

Joshi PP, Shegokar VR, Powar RM, Herder S, Katti R, Salkar HR et al. (2005). Human trypanosomiasis caused by Trypanosoma evansi in India: the first case report. Am J Trop Med Hyg 73: 491-495.

Kaur M, Reed E, Sartor O, Dahut W, Figg WD (2002). Suramin's development: what did we learn? Invest New Drugs 20: 209-219.

Keiser J, Stich A, Burri C (2001). New drugs for the treatment of human African trypanosomiasis: research and development. Trends Parasitol 17: 42-49.

Kennedy PG (2006). Human African trypanosomiasis-neurological aspects. I Neurol 253: 411-416.

Kinabo LDB (1993). Pharmacology of existing drugs for animal trypanosomiasis. Acta Trop 54: 169-183.

Kremsner PG, Krishna S (2004). Antimalarial combinations. Lancet 364: 285-294.

Lanteri CA, Stewart ML, Brock JM, Alibu VP, Meshnick SR, Tidwell RR et al. (2006). Roles for the Trypanosoma brucei P2 transporter in DB75 uptake and resistance. Mol Pharmacol 70: 1585-1592.

Lanteri CA, Trumpower BL, Tidwell RR, Meshnick SR (2004). DB75, a novel trypanocidal agent, disrupts mitochondrial function in Saccharomyces cerevisiae. Antimicrob Agents Chemother 48 3968-3974.

Legros D, Evans S, Maiso F, Enyaru JCK, Mbulamberi D (1999). Risk factors for treatment failure after melarsoprol for Trypanosoma brucei gambiense trypanosomiasis in Uganda. Trans $R$ Soc Trop Med Hyg 93: 439-442.

Legros D, Ollivier G, Gastellu-Etchegorry M, Paquet C, Burri C, Jannin J et al. (2002). Treatment of human African trypanosomiasis - present situation and needs for research and development. Lancet Infect Dis 2: 437-440.

Levin VA, Csejtey J, Byrd DJ (1983). Brain, CSF, and tumor pharmacokinetics of alpha-difluoromethylornithine in rats and dogs. Cancer Chemother Pharmacol 10: 196-199.

Ludewig G, Williams JM, Li Y, Staben C (1994). Effects of pentamidine isethionate on Saccharomyces cerevisiae. Antimicrob Agents Chemother 38: 1123-1128.

MacLean L, Chisi JE, Odiit M, Gibson WC, Ferris V, Picozzi K et al. (2004). Severity of human African trypanosomiasis in East Africa is associated with geographic location, parasite genotype, and host inflammatory cytokine response profile. Infect Immun 72: 7040-7044.

Maina NW, Kunz C, Brun R (2006). Cryopreservation of Trypanosoma brucei gambiense in a commercial cryomedium developed for bull semen. Acta Trop 98: 207-211.

Maina NWN, Oberle M, Otieno C, Kunz C, Maeser P, Ndung'u JM et al. (2007). Isolation and propagation of Trypanosoma brucei gambiense from sleeping sickness patients in South Sudan. Trans Roy Soc Trop Med Hyg (in press).

Mäser P, Sutterlin C, Kralli A, Kaminsky R (1999). A nucleoside transporter from Trypanosoma brucei involved in drug resistance. Science 285: 242-244.

Mathis AM, Holman JL, Sturk LM, Ismail MA, Boykin DW, Tidwell RR et al. (2006). Accumulation and intracellular distribution of antitrypanosomal diamidine compounds DB75 and DB820 in African trypanosomes. Antimicrob Agents Chemother 50: 2185-2191.

Matovu E, Enyaru JCK, Legros D, Schmid C, Seebeck T, Kaminsky R (2001). Melarsoprol refractory T.b. gambiense from Omugo, northwestern Uganda. Trop Med Int Health 6: 407-411.

Matovu E, Stewart ML, Geiser F, Brun R, Maser P, Wallace LJM et al. (2003). Mechanisms of arsenical and diamidine uptake and resistance in Trypanosoma brucei. Eukaryot Cell 2: 1003-1008.

McCulloch R (2004). Antigenic variation in African trypanosomes: monitoring progress. Trends Parasitol 20: 117-121.

Meshnick SR, Blobstein SH, Grady RW, Cerami A (1978). Approach to development of new drugs for African trypanosomiasis. J Exp Med 148: 569-579.

Miezan TW, Bronner U, Doua F, Cattand P, Rombo L (1994). Longterm exposure of Trypanosoma brucei gambiense to pentamidine in vitro. Trans $R$ Soc Trop Med Hyg 88: 332-333. 
Millet R, Maes L, Landry V, Sergheraert C, Davioud-Charvet E (2002). Antitrypanosomal activities and cytotoxicity of 5-nitro-2-furancarbohydrazides. Bioorg Med Chem Lett 12: 3601-3604.

Milord F, Loko L, Ethier L, Mpia B, Pepin J (1993). Eflornithine concentrations in serum and cerebrospinal fluid of 63 patients treated for Trypanosoma brucei gambiense sleeping sickness. Trans $R$ Soc Trop Med Hyg 87: 473-477.

Mitsuya H, Popovic M, Yarchoan R, Matsushita S, Gallo RC, Broder S (1984). Suramin protection of T cells in vitro against infectivity and cytopathic effect of HTLV-III. Science 226: 172-174.

Moens F, Dewilde M, Ngato K (1984). Clinical-trial of nifurtimox in human African trypanosomiasis. Ann Soc Belg Med Trop 64: $37-43$.

Moore A, Richer M (2001). Re-emergence of epidemic sleeping sickness in southern Sudan. Trop Med Intl Health 6: 342-347.

Mukherjee A, Padmanabhan PK, Sahani MH, Barrett MP, Madhubala $\mathrm{R}$ (2006). Roles for mitochondria in pentamidine susceptibility and resistance in Leishmania donovani. Mol Biochem Parasitol 145: $1-10$.

Mutugi MW, Boid R, Luckins AG (1994). Experimental induction of suramin-resistance in cloned and uncloned stocks of Trypanosoma evansi using immunosuppressed and immunocompetent mice. Trop Med Parasitol 45: 232-236.

Na-Bangchang K, Doua F, Konsil J, Hanpitakpong W, Kamanikom B, Kuzoe F (2004). The pharmacokinetics of eflornithine (alphadifluoromethylornithine) in patients with late-stage T.b. gambiense sleeping sickness. Eur J Clin Pharmacol 60: 269-278.

Nishimura K, Yanase T, Araki N, Ohnishi Y, Kozaki S, Shima K et al. (2006). Effects of polyamines on two strains of Trypanosoma brucei in infected rats and in vitro culture. J Parasitol 92: 211-217.

Njiokou F, Laveissiere C, Simo G, Nkinin S, Grebaut P, Cuny G et al. (2006). Wild fauna as a probable animal reservoir for Trypanosoma brucei gambiense in Cameroon. Infect Genet Evol 6: 147-153.

O'Kane RL, Vina JR, Simpson I, Zaragoza R, Mokashi A, Hawkins RA (2006). Cationic amino acid transport across the blood-brain barrier is mediated exclusively by system y+. Am J Physiol Endocrinol Metab 291: 412-419.

Pal A, Hall BS, Field MC (2002). Evidence for a non-LDL-mediated entry route for the trypanocidal drug suramin in Trypanosoma brucei. Mol Biochem Parasitol 122: 217-221.

Paulos C, Paredes J, Vasques I, Thambo S, Arancibia A, GonzalesMartin G (1989). Pharmacokinetics of a nitrofuran compound, nifurtimox, in healthy volunteers. Int J Clin Pharmacol Ther Toxicol 9: 454-457.

Pays E, Vanhollebeke B, Vanhamme L, Paturiaux-Hanocq F, Nolan DP, Perez-Morga D (2006). The trypanolytic factor of human serum. Nat Rev Microbiol 4: 477-486.

Pécoul B, Chirac P, Trouiller P, Pinel J (1999). Access to essential drugs in poor countries: a lost battle? JAMA 281: 361-367.

Pepin J, Milord F (1994). The treatment of human African trypanosomiasis. Adv Parasitol 33: 1-47.

Pepin J, Milord F, Meurice F, Ethier L, Loko L, Mpia B (1992). Highdose nifurtimox for arseno-resistant Trypanosoma brucei gambiense sleeping sickness: an open trial in central Zaire. Trans $R$ Soc Trop Med Hyg 86: 254-256.

Pepin J, Milord F, Mpia B, Meurice F, Ethier L, DeGroof D et al. (1989b). An open clinical trial of nifurtimox for arseno-resistant Trypanosoma brucei gambiense sleeping sickness in central Zaire. Trans R Soc Trop Med Hyg 83: 514-517.

Pepin J, Mpia B (2006). Randomized controlled trial of three regimens of melarsoprol in the treatment of Trypanosoma brucei gambiense trypanosomiasis. Trans $R$ Soc Trop Med Hyg 100: 437-441.

Pepin J, Milord F, Guerin C, Mpia B, Ethier L, Mansinsa D (1989a). Trial of prednisolone for prevention of melarsoprol-induced encephalopathy in gambiense sleeping sickness. Lancet 1: 1246-1250.

Peregrine AS, Mamman M (1993). Pharmacology of diminazene - a review. Acta Trop 54: 185-203.

Phillips MA, Coffino P, Wang CC (1987). Cloning and sequencing of the ornithine decarboxylase gene from Trypanosoma brucei. Implications for enzyme turnover and selective difluoromethylornithine inhibition. J Biol Chem 262: 8721-8727.
Phillips MA, Coffino P, Wang CC (1988). Trypanosoma bruce ornithine decarboxylase: enzyme purification, characterization, and expression in Escherichia coli. J Biol Chem 263: 17933-17941.

Phillips MA, Wang CC (1987). A Trypanosoma brucei mutant resistant to alpha-difluoromethylornithine. Mol Biochem Parasitol 22: 9-17.

Priotto G, Fogg C, Balasegaram M, Erphas O, Louga A, Checchi F et al. (2006). Three drug combinations for late-stage Trypanosoma brucei gambiense sleeping sickness: a randomized clinical trial in Uganda. PLoS Clin Trials 1: e39.

Rane L, Rane DS, Kinnamon KE (1976). Screening large numbers of compounds in a model based on mortality of Trypanosoma rhodesiense infected mice. Am J Trop Med Hyg 25: 395-400.

Raz B, Iten M, GretherBuhler Y, Kaminsky R, Brun R (1997). The Alamar Blue(R) assay to determine drug sensitivity of African trypanosomes (T.b. rhodesiense and T.b. gambiense) in vitro. Acta Trop 68: 139-147.

Remme JH, Blas E, Chitsulo L, Desjeux PM, Engers HD, Kanyok TP et al. (2002). Strategic emphases for tropical diseases research: a TDR perspective. Trends Parasitol 18: 421-426.

Roberts SC, Jiang Y, Gasteier J, Frydman B, Marton LJ, Heby O et al. (2006). Leishmania donovani polyamine biosynthetic enzyme overproducers as tools to investigate the mode of action of cytotoxic polyamine analogs. Antimicrob Agents Chemother 51: 438-445.

Robertson DH (1963). The treatment of sleeping sickness (mainly due to Trypanosoma rhodesiense) with melarsoprol. I. Reactions observed during treatment. Trans R Soc Trop Med Hyg 57: 122-133.

Romijn JC, Verkoelen CF, Splinter TA (1987). Problems of pharmacokinetic studies on alpha-difluoromethylornithine in mice. Cancer Chemother Pharmacol 19: 30-34.

Ross CA, Barns AM (1996). Alteration to one of three adenosine transporters is associated with resistance to cymelarsan in Trypanosoma evansi. Parasitol Res 82: 183-188.

Sands M, Kron MA, Brown RB (1985). Pentamidine - a review. Rev Infect Dis 7: 625-634.

Saulter JY, Kurian JR, Trepanier LA, Tidwell RR, Bridges AS, Boykin DW et al. (2005). Unusual dehydroxylation of antimicrobial amidoxime prodrugs by cytochrome b5 and NADH cytochrome b5 reductase. Drug Metab Dispos 33: 1886-1893.

Schmid C, Nkunku S, Merolle A, Vounatsou P, Burri C (2004). Efficacy of 10-day melarsoprol schedule 2 years after treatment for latestage gambiense sleeping sickness. Lancet 364: 789-790.

Schmid C, Richer M, Bilenge CM, Josenando T, Chappuis $F$, Manthelot CR et al. (2005). Effectiveness of a 10-day melarsoprol schedule for the treatment of late-stage human African trypanosomiasis: confirmation from a multinational study (IMPAMEL II). J Infect Dis 191: 1922-1931.

Schnaufer A, Domingo GJ, Stuart K (2002). Natural and induced dyskinetoplastic trypanosomatids: how to live without mitochondrial DNA. Int I Parasitol 32: 1071-1084.

Scott AG, Tait A, Turner CMR (1996). Characterisation of cloned lines of Trypanosoma brucei expressing stable resistance to MelCy and suramin. Acta Tropica 60: 251-262.

Scott AG, Tait A, Turner CMR (1997). Trypanosoma brucei: lack of cross-resistance to melarsoprol in vitro by cymelarsan-resistant parasites. Exp Parasitol 86: 181-190.

Shahi SK, Krauth-Siegel RL, Clayton CE (2002). Overexpression of the putative thiol conjugate transporter TbMRPA causes melarsoprol resistance in Trypanosoma brucei. Mol Microbiol 43: $1129-1138$.

Simo G, Asonganyi T, Nkinin SW, Njiokou F, Herder S (2006). High prevalence of Trypanosoma brucei gambiense group 1 in pigs from the Fontem sleeping sickness focus in Cameroon. Vet Parasitol 139: $57-66$.

Simpson L (1986). Kinetoplast DNA in trypanosomatid flagellates. Int Rev Cytol 99: 119-179.

Smith AB, Esko JD, Hajduk SL (1995). Killing of trypanosomes by the human haptoglobin-related protein. Science 268: 284-286.

Stanghellini A, Josenando T (2001). The situation of sleeping sickness in Angola: a calamity. Trop Med Int Health 6: 330-334.

Steck EA, Kinnamon KE, Davidson Jr DE, Duxbury RE, Johnson AJ, Masters RE (1982). Trypanosoma rhodesiense: evaluation of the antitrypanosomal action of 2,5-bis(4-guanylphenyl)furan dihydrochloride. Exp Parasitol 53: 133-144. 
Steinhoff D, Grundmann E (1972). Test for carcinogenicity of nifurtimox on oral and subcutaneous administration to rats. Arzneimittelforschung 22: 1607-1612.

Stewart ML, Bueno GJ, Baliani A, Klenke B, Brun R, Brock JM et al. (2004). Trypanocidal activity of melamine-based nitroheterocycles. Antimicrob Agents Chemother 48: 1733-1738.

Stewart ML, Krishna S, Burchmore RJS, Brun R, de Koning HP, Boykin DW et al. (2005). Detection of arsenical drug resistance in Trypanosoma brucei with a simple fluorescence test. Lancet 366: 486-487.

Sturk LM, Brock JL, Bagnell CR, Hall JE, Tidwell RR (2004). Distribution and quantitation of the anti-trypanosomal diamidine 2,5-bis(4-amidinophenyl)furan (DB75) and its $N$-methoxy prodrug DB289 in murine brain tissue. Acta Trop 91: 131-143.

Szyniarowski P, Bettendorff L, Schweingruber ME (2006). The antitrypanosomal drug melarsoprol competitively inhibits thiamine uptake in mouse neuroblastoma cells. Cell Biol Toxicol 22: 183-187.

Trouiller P, Olliaro P, Torreele E, Orbinski J, Laing R, Ford N (2002). Drug development for neglected diseases: a deficient market and a public-health policy failure. Lancet 359: 2188-2194.

Truc P, Jamonneau V, N'Guessan P, N'Dri L, Diallo PB, Cuny G (1998). Trypanosoma brucei ssp. and $T$ congolense: mixed human infection in Cote d'Ivoire. Trans $\mathrm{R}$ Soc Trop Med Hyg 92: 537-538.

Vanhollebeke B, Truc P, Poelvoorde P, Pays A, Joshi PP, Katti R et al. (2006). Human Trypanosoma evansi infection linked to a lack of apolipoprotein L-I. N Engl J Med 355: 2752-2756.

Vanschaftingen E, Opperdoes FR, Hers HG (1987). Effects of various metabolic conditions and of the trivalent arsenical melarsen oxide on the intracellular levels of fructose 2,6-bisphosphate and of glycolytic-intermediates in Trypanosoma brucei. Eur J Biochem 166: 653-661.

Vansterkenburg ELM, Coppens I, Wilting J, Bos OJM, Fischer MJE, Janssen LHM et al. (1993). The uptake of the trypanocidal drug suramin in combination with low-density lipoproteins by Trypanosoma brucei and its possible mode of action. Acta Trop 54: 237-250.

Viode $\mathrm{C}$, Bettache $\mathrm{N}$, Cenas $\mathrm{N}$, Krauth-Siegel R, Chauvière G, Bakalara N et al. (1999). Enzymatic reduction studies of nitroheterocycles. Biochem Pharmacol 57: 549-557.
Voogd TE, Vansterkenburg ELM, Wilting J, Janssen LHM (1993). Recent research on the biological activity of suramin. Pharmacol Rev 45: 177-203.

Vreysen MJ, Saleh KM, Ali MY, Abdulla AM, Zhu ZR, Juma KG et al. (2000). Glossina austeni (Diptera: Glossinidae) eradicated on the island of Unguja, Zanzibar, using the sterile insect technique. J Econ Entomol 93: 123-135.

Waddy BB (1970). Chemoprophylaxis of human trypanosomiasis. In: Mulligan HW (ed). The African Trypanosomiases. Allan \& Unwin: London, pp 711-725.

Wang MZ, Saulter JY, Usuki E, Cheung YL, Hall M, Bridges AS et al. (2006). CYP4F enzymes are the major enzymes in human liver microsomes that catalyze the $O$-demethylation of the antiparasitic prodrug DB289 [2,5-bis(4-amidinophenyl)furan-bis-O-methylamidoxime]. Drug Metab Dispos 34: 1985-1994.

Werbovetz K (2006). Diamidines as antitrypanosomal, antileishmanial and antimalarial agents. Curr Opin Investig Drugs 7: 147-157.

Wierenga RK, Swinkels B, Michels PA, Osinga K, Misset O, Van Beeumen J et al. (1987). Common elements on the surface of glycolytic enzymes from Trypanosoma brucei may serve as topogenic signals for import into glycosomes. EMBO J 6: 215-221.

Williamson J (1962). Chemotherapy and chemoprophylaxis of African trypanosomiasis. Exp Parasitol 12: 323-367.

Williamson J (1970). Review of chemotherapeutic and chemoprophylactic agents. In: Mulligan HW (ed). The African Trypanosomiases. Allen \& Unwin Ltd: London, pp 125-221.

Witola WH, Inoue N, Ohashi K, Onuma M (2004). RNA-interference silencing of the adenosine transporter-1 gene in Trypanosoma evansi confers resistance to diminazene aceturate. Exp Parasitol 107: 47-57.

Yarlett N, Bacchi CJ (1988). Effect of D,L-alpha-difluoromethylornithine on methionine cycle intermediates in Trypanosoma brucei brucei. Mol Biochem Parasitol 27: 1-10.

Yeates C (2003). DB289. Immtech International. iDrug 6: 1036-1093.

Yeramian P, Meshnick SR, Krudsood S, Chalermrut K, Silachamroon $\mathrm{U}$, Tangpukdee $\mathrm{N}$ et al. (2005). Efficacy of DB289 in Thai patients with Plasmodium vivax or acute, uncomplicated Plasmodium falciparum infections. J Infect Dis 192: 319-322.

Zweygarth E, Kaminsky R (1991). Evaluation of D,L-alpha-difluoromethylornithine against susceptible and drug-resistant Trypanosoma brucei brucei. Acta Trop 48: 223-232. 